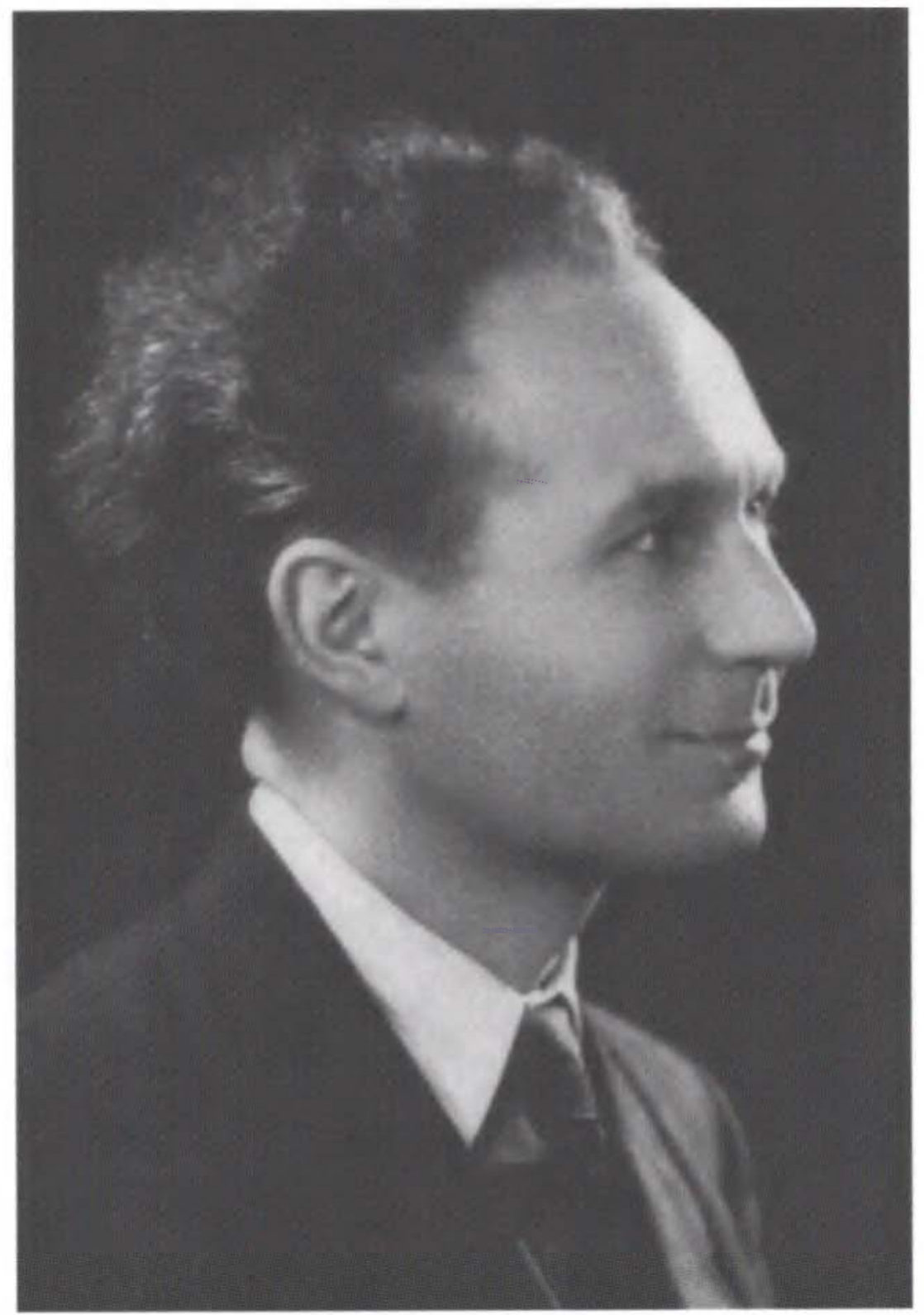

Eugen Ewig 


\title{
ULRICH PFEIL
}

\section{EUGEN EWIG}

\author{
"Créer un ordre transnational« \\ Von einem Mittler zwischen Deutschland und Frankreich
}

Eugen Ewig (1913-2006), ehemaliger Direktor und Vorsitzender des wissenschaftlichen Beirats des Deutschen Historischen Instituts Paris*, gehört nach Meinung seines Schülers und heutigen Präsidenten der Monumenta Germaniae Historica (MGH), Rudolf Schieffer, im Bereich der frühmittelalterlichen Geschichte zu denjenigen, die das sneue Bild entscheidend mitgestaltet [haben], das sich seit 1945 durchgesetzt hat und die gemeinsamen Wurzeln der europäischen Völker in den Vordergrund treten läßt«'. Ewig wäre jedoch nicht der einzige, so zeigen neuere Forschungen zum Verhalten deutscher Historiker in der Nachkriegszeit ${ }^{2}$, der die europäische Zusammenarbeit nach 1945 neu entdeckte und auch zur Grundlage seines wissenschaftlichen Arbeitens machte. Nicht wenige hatten dabei im Konkurrenzkampf um neue Ressourcen eine kapitale Kehrtwendung vollzogen, nachdem sie sich in den vorangegangenen Jahren z.T. dem historiographischen Grenz- und Abwehrkampf verschrieben hatten ${ }^{3}$. So wird auch für Ewig neben dem prägenden soziokulturellen Kontext

- Dieser Beitrag ist eine erweiterte Fassung von: Ulrich PfEIL, Eugen Ewig. Ein rheinischkatholischer Historiker zwischen Deutschland und Frankreich, in: François BEILECKE, Katja MarmetschKe (Hg.), Der Intellektuelle und der Mandarin. Für Hans Manfred Bock, Kassel 2005, S. 527-552. Die persönlichen Papiere von Eugen Ewig, die seine Familie dem DHIP freundlicherweise nach seinem Tod (1.3.2006) zur Verfügung stellte, ließen es berechtigt erscheinen, die neuen Kenntnisse dem interessierten Leser zugänglich zu machen. Ich danke Eugen Ewig für die Bereitschaft, mich noch am 14.1.2005 zu einem Gespräch empfangen zu haben; vgl. auch: In Memoriam Eugen Ewig (18.05.1913-01.03.2006). Reden bei der Akademischen Gedenkfeier am 1. Dezember 2006 im Festsaal der Rheinischen Friedrich-Wilhelms-Universität Bonn (Alma Mater 101), Bonn 2007.

1 Rudolf SCHIEFFER (Hg.), Beiträge zur Geschichte des Regnum Francorum: Referate beim wissenschaftlichen Colloquium zum 75. Geburtstage von Eugen Ewig am 28. Mai 1988, Sigmaringen 1990, S. 5.

2 Vgl. Sebastian CONRAD, Geographie und soziale Struktur. Die Frage nach dem Kern der Nation in Japan und der Bundesrepublik nach 1945, in: DERS., Christoph CONRAD (Hg.), Die Nation schreiben. Geschichtswissenschaft im internationalen Vergleich, Göttingen 2002, S. 112-136.

3 Vgl. Peter SCHÖTTLER, Von der rheinischen Landesgeschichte zur nazistischen Volksgeschichte oder Die munüberhörbare Stimme des Blutes«, in: Winfried SCHULZE, Otto Gerhard OEXLE (Hg.), Deutsche Historiker im Nationalsozialismus, Frankfurt a.M. 1999, S. 89-113. 
herauszuarbeiten sein, welches Wissenschaftsverständnis seiner Arbeit als Historiker vor dem Hintergrund sich wandelnder politischer Herausforderungen zugrunde lag. Auszugehen ist dabei von der These, daß Geschichtsschreibung in ihrem sozialen Raum immer auch von wissenschaftsfernen Aspekten beeinflußt wird ${ }^{4}$. Neben gesellschaftlichen, lebensweltlichen und materiellen Determinanten versprechen gerade wissenschaftssoziologische Fragestellungen neue Erkenntnisse, wenn wir dem spezifischen Wirkungszusammenhang von Wissenschaft und Politik auf die Spur kommen wollen'.

Die Kontinuitäten und Brüche über die verschiedenen politischen Systeme hinweg sind im Lebensweg von Eugen Ewig neben seinem Wirken als Historiker gerade nach 1945 auch von einem Handeln als Mittler zwischen Deutschland und Frankreich bzw. den Geschichtswissenschaften beider Länder geprägt gewesen. Beide Tätigkeiten lassen sich jedoch weder in Theorie noch in Praxis voneinander trennen, bildeten die in der oben zitierten Eloge erwähnten wissenschaftlichen Leistungen doch erst das kulturelle Kapital, das zu den typischen Wesensbedingungen von Mittlern gehört und sie soziologisch in die Nähe von Intellektuellen bringen. Nach Hans Manfred Bock kommt dabei Mittlern die Aufgabe zu, »den Mitbürgern des eigenen Landes die besonderen Denk- und Sichtweisen des Nachbarlandes zu erklären und dort Verständnis für sein Herkunftsland zu wecken ${ }^{6}$. In ihrer transnationalen Schrittmacherrolle zeichnen sich diese nationalkulturellen Übersetzungsarbeiter durch die Fähigkeit zu übernationalem Denken, Fühlen und Handeln aus, die sie unterhalb der offiziellstaatlichen Handlungsebene zum Einsatz bringen. Durch eine »Politik der kleinen Schritte« arbeiten diese zivilgesellschaftlichen Akteure in ihrem Wirkungsfeld sauf eine dauerhafte und gesellschaftlich verankerte Verständigung und Annäherung zwischen zwei Völkern« hin, wie Katja Marmetschke schreibt? Welchen Beitrag Eugen Ewig während seiner akademischen Karriere für die deutsch-französische Annäherung nach 1945 und damit für politische Zwecke leistete, soll im Mittelpunkt dieses Beitrages stehen, der darüber hinaus nach den Konstituierungs- und Wirkungsbedingungen einer von der Forschung bislang wenig beachteten Mittlerperson fragen will ${ }^{8}$.

4 Vgl. Lutz RaPHAEL, Diskurse, Lebenswelten und Felder. Implizite Vorannahmen über das soziale Handeln von Kulturproduzenten im 19. und 20. Jahrhundert, in: Wolfgang HARDTWIG u.a. (Hg.), Kulturgeschichte heute, Göttingen 1996, S. 165-181.

s Vgl. Georg G. IGGERS, Probleme einer Geschichte der deutschen Geschichtsschreibung, in: Jan M. BROEKMAN, Jan KNOPF (Hg.), Konkrete Reflexion. FS Hermann Wein, Den Haag 1975, S. 135-154.

- Hans Manfred BOCK, Vom Beruf des kulturellen Übersetzens zwischen Deutschland und Frankreich, oder Versagen die Mittler?, in: Lendemains 22 (1997) 86/87, S. 8-19, hier S. 9.

7 Katja MARMETSCHKE, Mittlerpersönlichkeiten. Neuere biographische Arbeiten zur Mittlerfunktion zwischen Frankreich und Deutschland, in: Lendemains 25 (2000) 98/99, S. 239-257, hier S. 239.

$8 \mathrm{Vgl}$. zu Eugen Ewig als Mediävist den Beitrag von Reinhold Kaiser in diesem Band. 
Intellektuelle und akademische Prägungen eines jungen Mediävisten

Der am 18. Mai 1913 in Bonn geborene und in einem katholischen Elternhaus aufgewachsene Eugen Ewig erwarb im Jahre 1931 seine Hochschulreife am humanistischen Beethoven-Gymnasium seiner Geburtsstadt. Er schrieb sich daraufhin an der Alma mater seiner Heimatstadt ein und begann in bewegter Zeit sein Studium der Fächer Geschichte, Deutsch und Französisch ${ }^{9}$. Letzteres Fach war anfangs keine Herzensangelegenheit des jungen Studenten; das sollte sich jedoch ändern, als er 1932 nach einem Ferienkurs in Dijon nach Paris kam und von einem »coup de foudre « ereilt wurde: »Mein von der Jugendbewegung geprägtes Weltbild wurde zwar nicht ganz verdrängt, aber erheblich korrigiert und relativiert durch das Erlebnis der französischen Metropole « ${ }^{10}$. Zurück in Bonn wurde er Zeuge, wie seine Universität von nationalsozialistischen Ideen heimgesucht wurde, die jedoch unter den Studenten weit mehr Anklang fanden als unter den Hochschullehrern. Schon 1932 warnte sein Lehrer Ernst Robert Curtius (1886-1956) in »Deutscher Geist in Gefahr« vor dem "vulgären Zerrbild« des Nationalsozialismus". Während der große Bonner Romanist aber nach 1933 trotz aller Kritik in der NS-Presse von den verschiedenen »Säuberungswellen« verschont blieb, mußte Ewig mit ansehen, wie sein ehemaliger Französischlehrer Hermann Platz (1880-1945), dem Curtius 1924 eine Honorarprofessur verschafft hatte, aus dem Amt gedrängt wurde ${ }^{12}$. Das Preußische Ministerium für Wissenschaft, Kunst und Volksbildung entzog ihm am 7. März 1935 den Lehrauftrag an der Universität Bonn, weil er - wie die Gauleitung Köln der NSDAP urteilte - zu den stypischsten Vertretern des Novembersystems« zähle und sich durch eine frankophile Grundhaltung auszeichne ${ }^{13}$.

Für Ewigs geschichtswissenschaftlichen Lehrer Wilhelm Levison (18761947) wurde der Rassenwahn der Nationalsozialisten schnell zu einer lebensgefährlichen Bedrohung. Zwar erfreute sich dieser renommierte Experte des frühen Mittelalters jüdischen Glaubens noch im Sommersemester 1933 unge-

9 Vgl. Ruth Baron, Professor Dr. Eugen Ewig, in: Staats-Zeitung 14 (1963) 52, S. 5.

10 Text der aus Anlaß seines 90. Geburtstags von Eugen Ewig in Bonn auf der Akademischen Festveranstaltung in Bonn gehaltenen Rede, 30.5.2003 (Privatpapiere Paravicini).

"Vgl. Hans Manfred BOCK, Die Politik des »Unpolitischen«. Zu Emst Robert Curtius' Ort im politisch-intellektuellen Leben der Weimarer Republik, in: Lendemains 15 (1990) 59, S. 16-62.

12 Vgl. Hans Manfred BOCK, Les intellectuels allemands à la recherche de l'Europe et d'une "Allemagne européenne« de 1945 à 1949, in: Andrée BACHOUD u.a. (Hg.), Les Intellectuels et l'Europe de 1945 à nos jours, Paris 2000, S. 91-102, hier S. 93.

13 Zitiert nach Winfried BECKER, Wegbereiter eines abendländischen Europa: Der Bonner Romanist Hermann Platz (1880-1945), in: Rheinische Vierteljahrsblätter 70 (2006), S. 236-260, hier S. 253. 
brochener studentischer Zuhörerschaft ${ }^{14}$ und der Solidarität seiner Kollegen, doch traf auch ihn schließlich der Bann der akademischen Ausgrenzung. Im Jahre 1935 wurde er im Alter von 59 Jahren trotz seiner »überzeugt nationalen Gesinnung " und gegen den Widerstand der Bonner Fakultät in den Ruhestand versetzt ${ }^{15}$. Im folgenden Jahr, als die Wehrmacht in das entmilitarisierte Rheinland einmarschierte, promovierte Ewig bei Max Braubach, der auf einem Lehrstuhl saß, der seit einer Kabinettsordre von 1853 einem Katholiken zustand. Das Hauptgutachten der Dissertation stammte aber »selbstverständlich aus Levisons Feder ${ }^{16}$, wie sich Ewig aus Anlaß des 60. Geburtstages von Braubach erinnerte: "Als mein Lehrer haben Sie meinen Studiengang kaum weniger geleitet als W. Levison, für den Sie ja auch bei meiner Dissertation einsprangen ${ }^{17}$. Ewig wie u.a. auch die Levison-Schüler Paul Egon Hübinger und Theodor Schieffer hielten in diesen Jahren den privaten Kontakt zu ihrem akademischen Lehrer, dem sie das 1935 erschienene Werk des später im Krieg umgekommenen Carl Erdmann "Die Entstehung des Kreuzzugsgedankens« »dedizierten ${ }^{18}$. Es war daher Ausdruck für die Wertschätzung, die Ewig seinem Lehrer entgegenbrachte, daß er bei den Planungen für die Gründung einer deutschen-historischen Forschungsstelle in Paris in den 1950er Jahren kurzzeitig mit dem Gedanken spielte, diese Institution »Centre Wilhelm Levison« zu nennen ${ }^{19}$.

Nach der Promotion gelang es Ewig noch einmal, für drei Monate nach Paris zu fahren, wie er sich 2003 erinnerte: "Es ist heute schwer vorstellbar, was dieser Ausstieg aus dem Gefängnis Deutschland bedeutete « ${ }^{20}$. Im Januar 1938 legte Eugen Ewig das Staatsexamen $a^{21}$, doch verspürte er aufgrund der politischen Verhältnisse nicht den Drang, nun auch den Weg als Lehrer in die Schule zu gehen. Kurzzeitig konnte er sich als Nachfolger seines Studien-

14 Vgl. Max BraUbaCH, Kleine Geschichte der Universität Bonn 1818-1968, Bonn 1967, S. 45; Dietrich HÖROLDT $(\mathrm{Hg}$.), Bonn. Von einer französischen Bezirksstadt zur Bundeshauptstadt 1794-1989, Bd. 4, Bonn 1989, S. 526.

15 Verschleppung und Ermordung kam er zuvor, weil er gemeinsam mit seiner Frau im April 1939 in die britische Universitätsstadt Durham emigrierte; vgl. Jürgen PETERSOHN, Deutschsprachige Mediävistik in der Emigration. Wirkungen und Folgen des Aderlasses der NS-Zeit (Geschichtswissenschaft - Rechtsgeschichte - Humanismusforschung,) in: HZ 277 (2003) 1, S. 1-60.

16 Karl Ferdinand WERNER, Zum Geleit, in: Eugen EwlG, Spätantikes und Fränkisches Gallien. Gesammelte Schriften (1952-1973), hg. von Hartmut ATSMA, 1. Band, München 1976, S. IX-XII.

17 Eugen Ewig an Max Braubach, 11.4.1959; UA Bonn, NL Braubach, Bd. 199.

$18 \mathrm{Vgl}$. Wilhelm Levison an Paul Egon Hübinger, 14.5.1945; UA Bonn, NL Hübinger, Bd. 77.

19 Eugen Ewig an Max Braubach, 6.9.1957; UA Bonn, NL Max Braubach, Bd. 156.

20 Text der am 30. Mai 2003 in Bonn auf der Akademischen Festveranstaltung in Bonn gehaltenen Rede; Privatpapiere Werner Paravicini.

21 Vgl. Zeugnis über die Wissenschaftliche Prüfung für das Lehramt an Höheren Schulen, 21.1.1938; Privatpapiere Eugen Ewig. 
freundes Paul Egon Hübinger als Bücherwart am Historischen Seminar der Universität Bonn verdingen, doch dies war nur ein Notbehelf. Bei der Entscheidungsfindung über seinen zukünftigen Weg spielten weniger wissenschaftliche als vielmehr politische Kriterien eine wichtige Rolle. Wissenschaft im »Dritten Reich» sah sich allgemein dem Druck ausgesetzt, die NSWeltanschauung als Grundlage ihrer wissenschaftlichen Tätigkeit zu übernehmen. Gleichzeitig wurden vor allem Nachwuchswissenschaftler bei Stellenbesetzungen politisch überprüft, was überdurchschnittlich viele Vertreter des akademischen Nachwuchses zu politischen Zugeständnissen veranlaßte, um die Aufstiegschancen zu wahren und das Ordinariat als Krönung einer jeden wissenschaftlichen Karriere doch noch zu erreichen ${ }^{22}$.

Jungen katholischen Historikern wie Ewig stand dieser Weg jedoch nicht offen. Nachdem sich Heinrich Büttner (1908-1970) bereits 1931 entschlossen hatte, am Institut für Archivwissenschaft und geschichtswissenschaftliche Fortbildung in Berlin-Dahlem den dreisemestrigen Ausbildungsgang für den Archivdienst zu durchlaufen, folgten u.a. Paul Egon Hübinger (1911-1987) und Theodor Schieffer (1910-1992) im Jahre 1937. Hübingers Entscheidung veranlaßte schließlich auch Ewig dazu, sich am Dahlemer Institut einzuschreiben. Dem Anpassungsdruck entgingen sie jedoch auch dort nicht, denn die Archivarausbildung sollte in die Verbeamtung münden, die durch einen Parteieintritt spürbar beschleunigt werden konnte. Nachdem Büttner bereits am 1. Juli 1933 der SA beigetreten warr ${ }^{23}$, beugten sich auch Theodor Schieffer ${ }^{24}$ und Stephan Skalweit (1914-2003) ${ }^{25}$. Hübinger gelang es, sich diesem Schritt

22 Michael GRÜTTNER, Wissenschaft, in: Wolfgang BENZ u.a. (Hg.), Enzyklopädie des Nationalsozialismus, München 1997, S. 135-153, hier S. 144.

23 Nachdem die Mitgliedersperre der NSDAP am 1.5.1937 vorübergehend aufgehoben worden war, beantragte Büttner am 20.5. die NSDAP-Mitgliedschaft und wurde rückwirkend zum 1.5. mit der Mitgliedsnummer 4715393 aufgenommen; BArchB, R3 (ehem. BDC) NSDAP-Gaukartei, Büttner, Heinrich.

${ }^{24}$ Er hatte seine Aufnahme am 4.10.1939 beantragt und war mit Wirkung vom 1.12.1939 Mitglied der NSDAP geworden (Mitgliedsnummer: 7280 318); BArchB (ehem. BDC) NSDAP-Gaukartei, Schieffer, Theodor.

25 Vgl. den Beitrag von Matthias PAPE in diesem Band. Anhaltspunkte finden sich bei: Stephan Skalweit an Paul Egon Hübinger, 23.11.1945; UA Bonn, NL Hübinger, Bd. 1; vgl. auch den "Persilschein« von Hübinger für Skalweit vom 23.2.1946, ibid., Bd. 2: "Als Student war Dr. Skalweit zum Eintritt in die SA gezwungen worden. Er suchte sich dem Dienst nach Möglichkeit zu entziehen. Als Mitglied der SA wurde er im September 1938 automatisch in die Partei überführt, ohne jemals einen Aufnahmeantrag gestellt zu haben. Er hat niemals irgendeine Aktivität in der Partei entfaltet. So konnte er trotz dieser formalen Zugehörigkeit niemals als Nazi gelten. Wenn dies anders gewesen wäre, würde auch eine freundschaftliche Beziehung mit ihm völlig unmöglich gewesen sein. Ich habe mich während der 12 Jahre der Naziherrschaft mit Erfolg der Eingliederung in die SA oder die Partei widersetzen können und stand stets in schärfster Opposition zum Nationalsozialismus und seinen Organisationen. Es war in dieser Zeit für bewußte Gegner des Naziregimes unmöglich, mit anderen als absolut zuverlässigen Gesinnungsgenossen engere per- 
zu entziehen. Ewig wurde während der Ausbildung aufgefordert, umgehend die Aufnahmepapiere zu unterschreiben, was er auch tat, doch hatte er das Glück, daß diese Entscheidung folgenlos blieb ${ }^{26}$.

Das anschließende Referendariat führte Ewig an das Staatsarchiv Breslau $(1940 / 41)^{27}$, wo der bekennende Rheinländer jedoch nicht heimisch wurde, so $\mathrm{da} ß$ er sich an den im Archivschutz in Luxemburg tätigen Oberarchivrat a.D. Wilhelm Kisky, ein ehemaliges Mitglied der Zentrumspartei, wandte. Dieser konnte ihm am 20. Januar 1941 mitteilen, daß Aloys Ruppel, Direktor des Staatsarchivs in $\mathrm{Metz}^{28}$, eine Hilfskraft brauchen könnte, so daß Kisky Ewig aufforderte, die nötigen Bewerbungsunterlagen nach Metz zu schicken ${ }^{29}$. Bereits Anfang 1941 hatte sich Ernst Zipfel (1891-1966), Generaldirektor der preußischen Staatsarchive, bereit erklärt, Ewig nach Metz abzuordnen, so daß Ruppel einen entsprechenden Antrag beim Chef der Zivilverwaltung in Lothringen stellte ${ }^{30}$. Da Ewig - seit 31. März 1941 Staatsarchivassessor ${ }^{31}$ - jedoch zum 1. April als Soldat zur Wehrmacht eingezogen wurde, bedurfte es einer UK-Stellung, um die Versetzung ins Metzer Archiv zu ermöglichen ${ }^{32}$. Ein Herzfehler befreite ihn schließlich vom Militärdienst, so daß sich Ewig Ende Mai 1941 auf den Weg nach Lothringen machen konnte ${ }^{33}$. Dort wurde er Stellvertreter von Ruppel ${ }^{34}$, den die Lothringer als Allemands d'avant qua-

sönliche Beziehungen zu unterhalten, weil die durch solche Beziehungen ausgelösten Gespräche andernfalls sofort zur Verhaftung geführt hätten«.

${ }^{26}$ Diesen Vorgang berichtete mir Eugen Ewig in einem Interview am 13.1.2005. In den Beständen des ehemaligen Berlin Document Centers befinden sich keine Hinweise auf eine Mitgliedschaft von Ewig.

27 Vgl. Preußisches Geheimes Staatsarchiv an Eugen Ewig, 4.7.1940; Privatpapiere Eugen Ewig.

28 Ruppel arbeitete von 1911 bis 1913 als Assistent am Bezirksarchiv Lothringen in Metz, dessen letzter kaiserlicher Direktor er zwischen 1914 und 1918 gewesen war. Seine ersten Kontakte zu Robert Schuman rühren noch aus dieser Zeit. Beide duzten sich, wie aus dem Glückwunschschreiben von Ruppel hervorgeht, das er Schuman anläßlich der Verleihung des Karlspreises im Jahre 1958 übersandte. Im gleichen Jahr war Ruppel auf Betreiben von Schuman vom französischen Staatspräsidenten René Coty das Kreuz der französischen Ehrenlegion verliehen worden, das ihm der französische Generalkonsul in Mainz angeheftet hatte; Aloys Ruppel an Robert Schuman, 21.12.1957; ARS, RS 29. Wilhelm Kisky an Eugen Ewig, 20.1.1941; Privatpapiere Eugen Ewig.

Aloys Ruppel an Eugen Ewig, 13.3.1941; ibid.

31 Ernst Zipfel an den Direktor der Staatsarchivs Breslau, 1.4.1941; ibid.

${ }^{32}$ Aloys Ruppel an Eugen Ewig, 7.5.1941; ibid.

${ }^{33}$ Vgl. Durchlaßschein Nr. 156, ausgestellt am 22.5.1941 in Breslau; vgl. allgemein: Wolfgang Freund, Volk, Reich und Westgrenze. Deutschtumswissenschaften und Politik in der Pfalz, im Saarland und im annektierten Lothringen 1925-1945, Saarbrücken 2006, S. $373 \mathrm{f}$.

34 Im Auftrag des Reichsstatthalters für die Westmark und Chef der Zivilverwaltung in Lothringen sollte Ruppel im September 1942 nach Paris reisen, um die »Feststellung des Umfangs des für die Rückgabe an das Metzer Staatsarchiv vorgesehenen Lothringischen 
torze (1914) bezeichneten ${ }^{35}$. Ihm war es gelungen, »der Gestapo die Autographensammlung des Abgeordneten Robert Schuman [zu entlocken], der im September 1940 von der Gestapo verhaftet worden war«, und sie ins Staatsarchiv zu überführen. Infolge von $»$ Reibungen mit der Zivilverwaltung in Lothringen ${ }^{36}$ bzw. weil er von der nationalsozialistischen Politik in Lothringen »angewidert« war, kehrte Ruppel im November 1942 nach Mainz zurück ${ }^{37}$. Zu seinem Nachfolger wurde Heinrich Büttner am 1. August 1943 ernannt, der dieses Amt aber nie wirklich antrat, weil er zur Wehrmacht eingezogen wur$\mathrm{de}^{38}$, so daß Ewig die kommissarische Leitung übernahm ${ }^{39}$.

In diese Zeit fielen Aktivitäten der Gauleitung Westmark, welche sich näher mit der romanisch-germanischen Sprachgrenze in Lothringen beschäftigten, wie Wolfgang Freund jetzt in seiner wichtigen und sorgfältig aus den Quellen erarbeiteten Studie aufzeigen konnte. Sie verdächtigte Ludwig XIV., »durch die Ansiedlung von Romanen das Deutschtum an der Sprachgrenze bewußt völkisch unterminiert zu haben ${ }^{40}$. Daher sollten nun gegenüber den Lothringern historische Ansprüche des deutschen Volkes auf die Moselle bewiesen werden. Damit schlug die "Stunde der Experten«, zu denen auch Eugen Ewig gehörte, der sich nunmehr zwischen dem wissenschaftlichen Ideal der akademischen Selbstbehauptung und dem totalitären Anspruch des NS-Regimes befand, Wissenschaft nach ihrem Nutzen für die »Volksgemeinschaft« zu beurteilen.

Im Staatsarchiv Nancy stieß Ewig auf die Landbeschreibung des Herzogtums Lothringen von Jahre 1585/86 und machte sich im Sommer 1943 an ihre Auswertung. Zwar konnte er nachweisen, daß sich Frankreich seit etwa 1663

Archivgutes aus den Archiven in Paris und Nancy« durchzuführen; AA an die deutsche Botschaft Paris, 18.9.1942; PA/AA, Botschaft Paris 1817-1944, Bd. 1110B.

35 Redetext vom 30. Mai 2003 (wie Anm. 20).

${ }^{36} \mathrm{Vgl}$. Wolfgang Hans STEIN (Hg.), Inventar von Quellen zur deutschen Geschichte in $\mathrm{Pa}$ riser Archiven und Bibliotheken (bearbeitet von einer Arbeitsgruppe unter Leitung von Georg Schnath), Koblenz 1986, S. XXXI.

37 Vgl. ausführlicher Wolfgang FREUND, Das Archivwesen im Gau Westmark, in: Robert KRETZSCHMAR u.a. (Hg.), Das deutsche Archivwesen und der Nationalsozialismus, Essen 2007, S. 326-341, hier S. 335ff.

38 Theodor Mayer an das Reichsministerium für Wissenschaft, Erziehung und Volksbildung, 10.9.1943; Archiv der Monumenta Germaniae Historica B 537, Bl. 4; FrEUND, Volk, Reich und Westgrenze (wie Anm.34), S. 319f. Der in Luxemburg stationierte Büttner kam alle 14 Tage nach Metz, wo er sich aber in erster Linie ausschlief, wie Ewig in der Rückschau berichtete: „Für mich wurde Büttner in der Metzer Zeit zum Mentor, der mir fortan als Wissenschaftler und als Freund zur Seite stand«; Redetext vom 30. Mai 2003 (wie Anm. 20).

39 Reichsstatthalter in der Westmark und Chef der Zivilverwaltung in Lothringen an Eugen Ewig, 15.10.1942; Privatpapiere Eugen Ewig; Ewig war am 9.11.1943 zum Archivrat ernannt worden; Reichsstatthalter in der Westmark und Chef der Zivilverwaltung in Lothringen an Eugen Ewig, 7.1.1944; ibid.

40 FreuND, Volk, Reich und Westgrenze (wie Anm. 34), S. 372. 
mit der Wiederbesiedlung des entvölkerten Landes beschäftigte, doch deutete seiner Meinung nach nichts darauf hin, daß Ludwig XIV. wirgendeine Form von ethnischer Politik « aus "nationalen Gesichtspunkten« betrieben habe, wie er in seiner am 23. Februar 1944 fertiggestellten Abhandlung über »Die Verschiebung der Sprachgrenze in Lothringen während des 17. Jahrhunderts« gegen den Strom einer expansionspolitischen Geschichtsschreibung feststellte:

Man hat die Vermutung geäußert, der französische König habe vor allem eigene Untertanen aus Innerfrankreich an die strategisch wichtige Straße Metz-Straßburg verpflanzen wollen. Die Quellen geben dafür keinen Anhalt. Das Dekret Ludwigs XIV. von 1680 richtet sich ausdrücklich nicht nur an seine Untertanen, sondern auch an die Ausländer. Die Maßnahmen des Königs waren also in erster Linie von seinem Interesse an der Kultivierung brachliegender Ländereien bestimmt [...]. So haben denn auch nicht nur Innerfranzosen, sondern ebenso deutschstämmige Siedler an dem Kultivierungswerk teilgenommen [...]. Nationale Gesichtspunkte lagen den Staatsmännern der Zeit im allgemeinen fern. Die Hebung der Landeskultur hatte die Erhöhung der territorialstaatlichen Einkünfte im Gefolge ${ }^{41}$.

Ewig stieß mit seiner These auf wenig Gegenliebe bei seinen Vorgesetzten und wahrte seine geschichtswissenschaftliche Integrität. Wie Wolfgang Freund herausarbeiten konnte, zeugt sein Verhalten während der Metzer Jahre von dem Willen, sich auch als Historiker und Archivar im Nationalsozialismus in der fachlichen Arbeit nicht den politischen Vorgaben zu beugen ${ }^{42}$.

Noch in den Räumen seines Archivs, das in der Präfektur untergebracht war, erlebte Ewig schließlich am 19. November 1944 den Beginn der Entscheidungsschacht um Metz. Als die Amerikaner die Stadt am 22. November befreiten ${ }^{43}$, verhandelte Ewig die Übergabe der Präfektur und wurde im Anschluß als deutscher Zivilist von den Amerikanern interniert. Aus dem Lager in Suzange nahm er brieflichen Kontakt zu Robert Schuman auf und stellte sich mit folgenden Worten vor: »Je suis Rhénan, élève du professeur Platz ${ }^{44}$. Über seine Arbeit als Archivar in Metz schrieb er:

J'ai toujours gardé les droits de la Lorraine sur ses archives, tant que cela m'était possible. Je n'ai pas pu éviter l'évacuation des registres d'état civil du Palais de Justice. Mais je me suis opposé formellement à l'évacuation des Archives Départementales et j'ai fait échouer l'envoi des registres de l'Évêché en Allemagne, en trainant l'affaire en longueur. J'ai rendu à l'Évêché ses archives saisies par la Gestapo. J'ai de même sauvé tout ce qui nous est parvenu de votre collection de documents historiques qui se trouve maintenant dans la cave de la Préfecture ${ }^{45}$.

41 Die Verschiebung der Sprachgrenze in Lothringen während des 17. Jahrhunderts (Ms.), 23.2.1944; Privatpapiere Eugen Ewig.

42 Vgl. Freund, Volk, Reich und Westgrenze (wie Anm. 34), S. 370-375.

43 Vgl. Francis Petitdemange, Jean-François Genet, Nos Libérateurs. Lorraine 1944, Nancy 2004, S. 160ff.

44 Eugen Ewig an Robert Schuman, 28.11.1944; Maison de Robert Schuman, conseil général de la Moselle (ARS), RS 25.

45 Ibid. 
Ewig schilderte in seinem Schreiben die unerträglichen hygienischen und sanitären Verhältnisse in dem Lager und bat abschließend Schuman, sich für seine Freilassung einzusetzen: »Je n'aurais jamais osé m'adresser à vous, si je ne savais pas que vous êtes chrétien«. Ewigs Anliegen wurde schon bald Erfolg beschieden, denn auf Bestreben lothringischer Freunde und nicht zuletzt Dank des Einsatzes von Robert Schuman ${ }^{46}$ wurde er am 1. Januar 1945 frühzeitig entlassen.

Von verschiedenen Seiten wurde ihm im Frühsommer 1945 tadelloses Verhalten bestätigt, so von seinem ehemaligen Sekretär im Metzer Archiv, Léon Thiel. In zahlreichen Gesprächen mit Ewig habe dieser ihm seine "sentiments antinazis« offenbart; zudem habe er sich immer für die Sache Lothringens eingesetzt und ihn bei seinem Entschluß im Frühjahr 1943 bestätigt, die Flucht nach Frankreich anzutreten ${ }^{47}$. Genauso bestätigte sein ehemaliger Mitarbeiter Pierre Noël, daß Ewig stets den Sieg der Alliierten herbeigewünscht habe und im Dienst Französisch gesprochen habe, so weit dies ohne Gefahr möglich gewesen sei. Ihn selber habe er vor der Zwangsrekrutierung für Befestigungsarbeiten im Herbst 1944 bewahrt. Gleichzeitig habe er den Transport der Archivbestände nach Deutschland verhindert, indem er sich krank gestellt und anschließend im Keller des Archivs versteckt habe ${ }^{48}$. Von anderer Seite konnte bezeugt werden, daß Ewig "auf der schwarzen Liste der Gauleitung Westmark stand und [nach der Rückeroberung Lothringens] fusilliert werden sollte«. Vorgeworfen wurde ihm u.a., "daß er die deutsche Besatzung der Präfektur zur Waffenstreckung veranlaßt « habe ${ }^{49}$. Auch Robert Schuman blieb Ewig verbunden, erhielt er doch seine Papiere zurück, wie Heinz Thomas zum 90. Geburtstag von Ewig nochmals schilderte: "Schuman hat ihn [...] gefragt, wo denn jene Papiere verblieben seien. Ewig wußte es, Schuman selbst hat ihn in das für Deutsche damals streng verbotene Archiv geführt und das mit Ewigs Namen signierte Dossier an sich nehmen können « ${ }^{50}$.

Eugen Ewig konnte während seiner Metzer Jahre das Vertrauen der mit ihm in Kontakt stehenden Lothringern erwerben, doch sollte dabei nicht vergessen werden, daß die Arbeit als deutscher Archivar in der annektierten Moselle immer politische Implikationen besaß. Deutsche Archivare waren in die von der Archivverwaltung unter Leitung von Ernst Zipfel definierten Ost- und

46 Walter Lipgens hatte über den belgischen Historiker Henri Bernard erfahren, daß Ewig während des Krieges in enger Verbindung zu Robert Schuman gestanden habe (Lipgens an Ewig, 7.5.1964; BAK, B 250, Bd. 3), was dieser bestätigte: »Ich habe Robert Schuman zwar nahegestanden, besitze aber keinerlei politische Dokumente, da ich selbst kein Politiker bin“ (Ewig an Lipgens, 7.9.1964; BAK, B 250, Bd. 5).

47 Certificat de Léon Thiel, 21.6.1945; Privatpapiere Eugen Ewig.

48 Certificat de Pierre Noël, 15.6.1945; ibid.

49 Certificat de Madeleine Fischer, 12.6.1945; ibid.

50 Heinz THOMAS, Der Erbfreund. Zum neunzigsten Geburtstag des Historikers Eugen Ewig, in: FAZ, 114/17.5.2003. 
Westprogramme eingebunden, die an sie immer auch politische Herausforderungen herantrugen, wie Zipfels Ausführungen aus dem Jahr 1941 verdeutlichen: »Mit der Durchführung dieser beiden Arbeitsprogramme [...] will die Archivverwaltung ihren Beitrag liefern zu den Aufgaben, die durch die Ausweitung des Reiches im Osten und Westen und seine neuerworbene Führerstellung in Europa der deutschen Geschichtswissenschaft aufgegeben worden sind ${ }^{51}$. Das Verhalten von Eugen Ewig während seiner Zeit in Metz verdeutlicht jedoch, daß sich dem Historiker bzw. Archivar trotz der ideologischen Überformung der Geschichte Handlungsspielräume boten, die es ihm erlaubten, die wissenschaftlichen Standards seiner Disziplin nicht über den Haufen zu werfen. Diese Haltung wurde im Falle von Ewig auch von der französischen Seite registriert, wie aus dem Schreiben von Jean de Pange an Robert Schuman vom 1. März 1948 deutlich wird: „Vous savez que de sympathies il s'est acquis pendant la guerre à Metz quand il y était chargé des archives « ${ }^{52}$.

\section{Milieuverbundenheit im katholischem Abend- und Rheinland}

Wenn wir uns im folgenden ausgedehnter mit dem oben bereits kurz angesprochenen Hermann Platz beschäftigen, so tun wir dieses erstens, weil er in Bonn regelmäßig Jugendliche und Studenten um sich versammelte ${ }^{53}$ und auch Eugen Ewig mit Abendland und französischer Kultur in Verbindung brachte. Dieser Romanist und Theologe gehört zu den vergessenen Mittlerpersönlichkeiten der Zwischenkriegszeit, obwohl er sich mit seinen Abhandlungen ${ }^{54}$ und der von ihm ab 1925 herausgegebenen Zeitschrift »Abendland « zum Vordenker für das rheinisch-katholische Milieu entwickelt hatte ${ }^{55}$. Zweitens erschließt

51 Ernst ZIPFEL, Die wissenschaftlichen Aufgaben der Archivverwaltung, 10.7.1941; HHStAW, 1150, Bd. 23, Bl. 272-274, hier Bl. 273.

52 Jean de Pange an Robert Schuman, 1.3.1948; ARS, RS 25.

53 Vgl. Vincent BERning, Hermann Platz, in: Neue Deutsche Biographie, Bd. 20, Berlin 2001, S. 519ff.

54 Hermann PLATZ, Deutschland und Frankreich. Versuch einer geistesgeschichtlichen Grundlegung der Probleme, Frankfurt a.M. 1930.

$55 \mathrm{Vgl}$. Heinrich LUTZ, Deutschland und die Idee des Abendlandes. Bemerkungen zum kulturellen und politischen Engagement von Hermann Platz vor und nach dem Ersten Weltkrieg, in: Vincent BERNING (Hg.), Hermann Platz (1880-1945). Eine Gedenkschrift, Düsseldorf 1980, S. 47-64; BOCK, Vom Beruf des kulturellen Übersetzens (wie Anm. 7), S. 10; Dagmar PÖPPING, Abendland. Christliche Akademiker und die Utopie der Antimoderne 1900-1945, Berlin 2002, S. 100ff.; Vanessa CONZE, Das Europa und die Deutschen. Ideen von Europa in Deutschland zwischen Reichstradition und Westorientierung (1920-1970), München 2005; Hans Manfred BocK, Der Abendland-Kreis und das Wirken von Hermann Platz im katholischen Milieu der Weimarer Republik, in: Michel GRUNEWALD, Uwe Puschner (Hg.), Das katholische Intellektuellenmilieu in Deutschland, 
sich uns ohne das Wissen um seinen intellektuellen Einfluß im soziokulturellen Spannungsfeld seiner Zeit weder das gesellschaftliche Handeln und noch der akademische Weg von Eugen Ewig. Der Umweg über Hermann Platz verspricht somit wichtige Hinweise auf Milieueingebundenheit und intellektuelle Prägungen, darüber hinaus nähern wir uns über seine Person politisch, ideengeschichtlich und soziologisch einem Beziehungsgeflecht, das den jüngeren Ewig Mitte der 1940er Jahre in die Nähe von Konrad Adenauer (1876-1967) und Robert Schuman (1886-1963) brachte.

Vor dem Ersten Weltkrieg gehörte Hermann Platz genauso wie Heinrich Brüning und Robert Schuman zum Kreis der Liturgischen Bewegung, die es sich zum Ziel gemacht hatte, die Liturgie volksnäher zu gestalten. In diese Zeit fiel auch bereits sein Engagement für eine Aussöhnung zwischen Frankreich und Deutschland ${ }^{56}$. Nach 1918 beteiligte er sich an der geistig-moralischen und geographischen Neuvermessung des nationalen Koordinatensystems ${ }^{57}$, indem er zugleich gegen den preußisch-deutschen und den französischen $\mathrm{Na}$ tionalismus wetterte ${ }^{58}$. Religiöse Rückbesinnung auf die mittelalterliche Einheit des Abendlandes als gemeinsamer intellektueller Raum für Deutsche und Franzosen blieb auch jetzt für Platz die Garantie für die Zukunft Europas ${ }^{59}$, in das ein "neues« Deutschland sein christliches Erbe einzubringen habe. Das Abendland war für ihn eine geschichtspolitische und kulturphilosophische Chiffre auf der Suche nach geistiger Substanz aus der Tradition heraus, die er in ostentativem Widerspruch zu Aufklärung, Säkularisierung und den Ideen der Französischen Revolution in dem idealisierten Bild des "abendländischen« Mittelalters suchte: "Das ferne Symbol ist die Krone Karls des Großen ${ }^{60}$. Dem Rheinland schrieb er auf dem Weg dorthin eine Schlüsselstellung zu: »Unser Sitz ist die Mitte. Die Mitte Europas, das ist klar. Aber auch die Mitte Deutschlands. Wir fühlen uns gar nicht als deutsches Grenzland, obwohl wir auch Randfunktionen ausüben. Wir fühlen uns als Ausgangspunkt, als Kern ${ }^{61}$. Im Gegensatz zu den Vertretern eines rheinischen Partikularismus trat er jedoch stets energisch für den Verbleib der Rheinlande bei Deutschland

seine Presse und seine Netzwerke (1871-1963). Le milieu intellectuel catholique en Allemagne, sa presse et ses réseaux (1871-1963), Bern u.a. 2006, S. 337-362.

s6 Vgl. Paul COLONGE, Hochland face à l'Europe (1918-1933), in: Michel Grunewald, Hans Manfred BOCK ( $\mathrm{Hg}$.), Le discours européen dans les revues allemandes (19181933), Bern 1997, S. 133-148, hier S. 139.

57 Hermann PlatZ, Deutschland - Frankreich und die Idee des Abendlandes. Flugschriften der Rheinischen Zentrumspartei. II. Folge - Heft 2 (1924), S. 15ff.

$58 \mathrm{Vgl}$. Richard FABER, Abendland. Ein politischer Kampfbegriff, Berlin, Wien 2002, S. 141.

59 Vgl. Hermann PLATZ, Das Ringen um die abendländische Idee, in: Hochland 20 (1923) 2, S. 308-318.

60 DERS., Um Rhein und Abendland, Burg Rothenfels a. R. 1924, S. 62.

61 DerS., Deutschland - Frankreich und die Idee des Abendlandes (wie Anm. 58), S. 19. 
$e^{62}{ }^{62}$ Winfried Becker würdigt das geistige Werk von Hermann Platz mit folgenden Worten: "Der Abendländer Platz vertrat eine dynamische Seinsmetaphysik, eine Ontologie, die auf einen historischen, epochen- und landschaftsgebundenen Ideenzusammenhang projiziert war [...], er bildete mit seinen Anwendungsbereichen, z.B. der Völkerversöhnung, einen so wohl nicht geplanten, aber de facto fundamentalen Gegenentwurf zur Rassenlehre, zur Blutund Bodenmystik des Nationalsozialismus ${ }^{63}$.

Es mag neben dem Einfluß von Wilhelm Levison, dem $» N e s t o r$ der rheinischen und fränkischen Geschichtsforschung “ ${ }^{64}$, auf Hermann Platz zurückzuführen sein, daß sich das spezielle Interesse des jungen Mediävisten Ewig auf den lotharingischen Raum bzw. die rheinischen Lande konzentrierte. In seiner ideengeschichtlich angelegten Dissertation über den Theologen und Mystiker Dionysius von Roermond ${ }^{65}$ befaßte er sich mit einem Spätscholastiker im Gelderschen (dem heutigen Limburg) aus der Zeit des Baseler Konzils (14311449), der auf seine Zeitgenossen durch seine theologischen und philosophischen Abhandlungen ausgeübt hatte. Seinen ersten längeren wissenschaftlichen Aufsatz veröffentlichte er 1939 in den "Annalen des Historischen Vereins für den Niederrhein ${ }^{66}$, die von den Nationalsozialisten als »klerikales Organ $\aleph^{67}$ mit Mißtrauen beobachtet und 1944 verboten wurden. Dagegen publizierte er seinen zweiten längeren Artikel 1943 in einem der einschlägigen Fachblätter der historischen "Westforschung ${ }^{68}$, die sich besonders mit dem deutschen "Volkstum" in den Grenzgebieten beschäftigte. Hatte sich auch Ewig mittlerweile der "großdeutschen Sache« angenommen bzw. zu einem Wissenschaftler fortentwickelt, der wie so viele Vertreter seiner Zunft die nationalsozialistische Expansionspolitik mit seiner geisteswissenschaftlichen Forschung legitimierte? Ließ sich etwa nun auch bei ihm »intellektuelle Konkordanz zwischen Forschung, Propaganda und Annexionsmaßnahmen ${ }^{69}$ feststellen?

Vgl. BECKER, Wegbereiter (wie Anm. 14), S. 249.

Ibid., S. 259.

${ }^{64}$ Rheinische Historiker tagten, in: Aachener Volkszeitung, 22.6.1946.

${ }^{65}$ Vgl. Eugen EwIG, Die Anschauungen des Kartäusers Dionysius von Roermond über den christlichen Ordo in Staat und Kirche, Bonn 1936.

6o Eugen EwIG, Die Wahl des Kurfürsten Joseph Clemens von Cöln zum Fürstbischof von Lüttich 1694, in: Annalen des Historischen Vereins für den Niederrhein 135 (1939), S. 41-79, hier S. 41 .

${ }^{67}$ Paul Egon Hübinger an Wilhelm Levison, 10.1.1947; UA Bonn, NL Hübinger, Bd. 4.

${ }^{68} \mathrm{Vgl}$. Eugen EwIG, Die Deutschordenskommende Saarburg, in: Elsaß-Lothringisches Jahrbuch, hg. vom Wissenschaftlichen Institut der Elsaß-Lothringer im Reich an der Universität Frankfurt a.M., XXI (1943), S. 81-126.

69 Peter SCHÖTTLER, Die historische , Westforschung ( zwischen >Abwehrkampf rialer Offensiver, in: DERS. (Hg.), Geschichtsschreibung als Legitimationswissenschaft 1918-1945, Frankfurt a.M. ${ }^{2} 1999$, S. 204-261, hier S. 215. 
Daß Ewig nicht dem rassischen 'turn der »Volksgeschichte« nach 1933 folgte bzw. den geschichtspolitischen Bestrebungen einer Germanisierung Lothringens das Wort redete, legen die Forschungen von Wolfgang Freund nahe, der auf den Aufsatz "Metz und das Reich im Mittelalter" gestoßen ist, den Ewig im Juni 1943 für die Lokalbeilage zur »NSZ Westmark«, den »Metzer Heimatbrief«, eingereicht hatte. Als er wenige Tage später die Zeitung aufschlug, "traute er seinen Augen nicht«, wie Freund kommentiert. Die Redaktion hatte sich als Zensor betätigt und alles entfernt, "was der nationalsozialistischen Geschichtsschreibung und der Germanisierungspolitik in Lothringen widersprach [...]. Lothringische Eigenständigkeit und Freiheitsliebe, Metzer Autonomie und Sonderstellung sollten der Vergessenheit anheimfallen«. Infolge dieser inhaltlichen Deformierungen und Sinnentstellungen lehnte Ewig jegliche Verantwortung für den veröffentlichten Artikel $a b^{70}$. Er weigerte sich weiterhin, den deutschen Kulturraum mit einem harmonisierten »deutschen Volkskörper« gleichzusetzen, auch wenn er als Vertreter eines landesgeschichtlichen Ansatzes bisweilen eine »organische Einheit" von Land und Volk postulierte und einem "Nexus von Raum und Bevölkerung « zuredete. Sein landsmannschaftlich-stammliches Zugehörigkeitsgefühl zum rheinischen Raum bewahrte ihn aber neben seiner abendländischen Gesinnung vor deutschtümelnd-ethnozentristischen Orientierungen ${ }^{71}$. Es kann daher nur wenig überraschen, da $\beta$ er nach seiner Befreiung aus der Internierung seinen Status als ,Wanderer zwischen beiden Welten« genoß. Er blieb für den Moment in Metz, ohne sich der Möglichkeit berauben zu wollen, jederzeit nach Deutschland reisen zu können.

\section{Aufbau von Dialogstrukturen über die nationalen Grenzen}

$\mathrm{Daß}$ Ewig zu allererst Rheinländer war, zeigte sich in aller Deutlichkeit nach dem Zusammenbruch des »Dritten Reiches«, als er sich frei in Frankreich bewegte, "wo er zu den eifrigsten Befürwortern eines Rheinstaates gehört«, wie sein Freund Hübinger im Januar $1946 \mathrm{zu}$ berichten wußte ${ }^{72}$. Zur gleichen Zeit verfaßte er einen mit "Bonn - Rheinland. $D^{r}$ Eugen Ewig" signierten Artikel, in dem er das Rheinland nicht nur als Tor des Westens nach Deutschland bezeichnete, sondern zugleich der Zentrumspartei vorwarf, sich nach dem Ersten

70 Vgl. die Einzelheiten dieses Hergangs und die zitierten Passagen in: FREUND, Volk, Reich und Westgrenze (wie Anm. 34), S. 373.

71 Zitate in: Willi OBERKROME, Entwicklungen und Varianten der deutschen Volksgeschichte (1900-1960), in: Manfred HETTLING (Hg.), Volksgeschichten im Europa der Zwischenkriegszeit, Göttingen 2003, S. 65-95.

72 Paul Egon Hübinger an Heinrich Büttner, 5.1.1946; UA Bonn, NL Hübinger, Bd. 1. 
Weltkrieg gegen eine Autonomie des Rheinlandes entschieden zu haben: "Le Centre sacrifia en 1919/23 l'autonomie rhénane et le fédéralisme allemand à la coalition socialo-centriste de Weimar [...]. Sacrifice inutile et dangereux, car il sanctionna en fin de compte la victoire de la Prusse sans changer la loi de l'État prussien « ${ }^{73}$. Hübinger bekleidete zu jener Zeit eine exponierte Stellung als persönlicher Referent des Oberpräsidenten der Nord-Rheinprovinz in Düsseldorf und war u.a. mit den separatistischen Strömungen befaßt. Obgleich er selber kein Anhänger eines rheinischen Separatismus war, beobachtete er Ewigs Mittlertätigkeiten mit Wohlwollen. So bot sich der langjährige Freund an, als Mittelsmann zwischen der rheinischen Metropole und der französischen Hauptstadt zu wirken; er wollte damit eine Rolle personifizieren, die er allgemein dem Rheinland zudachte: »La Rhénanie doit participer à la vie occidentale comme elle participe à la vie allemande. Ainsi seulement, le statut rhénan créera les conditions nécessaires à la renaissance d'une Allemagne européenne ${ }^{74}$.

In Paris verfügte Ewig über Kontakte zum Milieu der katholischen Linkspresse um die Zeitung »Temps Présent « (u.a. Wladimir d'Ormesson) und zum christdemokratisch-linkskatholischen Mouvement républicain populaire (MRP). Über dieses Sammelbecken der »Résistance catholique«, das Georges Bidault, Maurice Schumann, Robert Schuman u.a. zu seinen Vertretern zähl$\mathrm{te}^{75}$ und sich zur damaligen Zeit bereits gegen die breite öffentliche Meinung in Frankreich für eine deutsch-französische Aussöhnung aussprach, verfügte er über Kontakte zum französischen Außenministerium: "Ich habe also die Möglichkeit, Denkschriften beim Quai d'Orsay einzureichen und Artikel in der katholischen Presse zu veröffentlichen ${ }^{76}$.

Ewigs Vorstellungen von der Zukunft seiner rheinländischen Heimat beruhten auf seiner Abneigung gegen alles Preußische, wie er gegenüber Robert Schuman am 28. November 1945 zum Ausdruck brachte, acht Tage nach der Ernennung von Hermann Pünder (1888-1976) zum Kölner Oberbürgermeister, welcher ein Freund von Pastor Martin Niemöller (1892-1984) war: "Malgré les mérites du pasteur, cette mesure est à mon avis un affront à la population rhénane catholique. Niemöller est resté Prussien. Il n'y a rien à espérer de ce côté-là «" ${ }^{77}$. Ewigs Aversion gegen das Preußentum hatte seinen Ursprung nicht alleine in dem immer noch nicht vergessenen Kulturkampf, sondern vor allem in seinen unumstößlichen Bedenken gegen einen von Berlin

73 Eugen EwIG, L'avenir thénan, in: Jean DumonT (Hg.), Le Rhin. Nil de l'Occident, Paris 1947, S. 315-324, hier S. 318.

74 Ibid., S. 321.

75 Vgl. Michel WINOCK, Le siècle des intellectuels, Paris 1999, S. 525ff.; DERS. La France politique XIX'-XX' siècle, Paris 1999, S. 439f.

76 Paul Egon Hübinger an Wilhelm Levison, 27.3.1947; UA Bonn, NL Hübinger, Bd. 4.

77 Eugen Ewig an Robert Schuman, 28.11.1945; ARS, RS 25. 
aus regierten deutschen Nationalstaat. Er war ein Mann des Heiligen Römischen Reiches geblieben ${ }^{78}$, blieb der föderale Staatenbund im Herzen Europas für ihn doch auch jetzt die Grundlage für dauerhaften Frieden in Europa ${ }^{79}$, wie er Robert Schuman erklärte:

Mon attitude politique est inspirée par la tradition rhénane. J'entends servir mon pays rhénan, tout en étant convaincu que les intérêts de mon pays sont identiques à ceux de la France. Mes publications depuis 1938 prouvent que cette conviction ne date pas d'hier. Pour mener ma tâche à bien, il faut que je travaille des deux côtés de la frontière. Il s'agit de montrer aux Rhénans le vrai visage de la France et d'informer l'opinion publique en France sur la situation rhénane. Renvoyé en Allemagne (zone anglaise!) sans espoir de retour, je rentrerais dans un isolement qui ne me permettrait plus de poursuivre cette tâche. Permettez-moi à ce sujet une réflexion générale: le fédéralisme ou séparatisme allemand doit être considéré comme une étape vers une organisation européenne. Séparé de l'Europe, il est d'avance condamné à mort. L'indépendance rhénane est impossible à réaliser sans le concours de l'Europe. Impossible de faire quelque chose dans l'isolement [...]. Deux domiciles ou passeport - telles sont les conditions indispensables à mon travail. La première solution est celle que je préfère ${ }^{80}$.

Mit seinem Engagement für eine Annäherung zwischen Frankreich und den deutschen Rheinlanden stieß er bei seinen französischen Gesprächspartnern jedoch nicht immer auf Gegenliebe, wie er gegenüber Hübinger bekannte:

In der Annahme, daß die Unabhängigkeit der Rheinlande dem Interesse unserer Heimat am besten entspreche, habe ich in Frankreich den Unterschied zwischen dem deutschen Westen und den innerdeutschen Provinzen aufs schärfste betont. Ohne mich auf eine bestimmte Lösung festzulegen (deutsche Confoederation, niederländische Confoederation, volle Unabhängigkeit), habe ich den Plan propagiert, aus unserer Heimat eine Art rheinisches Österreich zu machen. Weit entfernt, dabei allgemeinen Beifall zu finden, hatte ich vielmehr gegen starke Skepsis und politische Bedenken zu kämpfen. Man fürchtet, daß ein selbständiger Rheinstaat sich allzu schnell erholen werde und daß ein katholisch-demokratischer Nachbar auf ElsaßLothringen eine besondere Anziehungskraft ausüben könnte. Nach meiner Meinung gibt uns der Föderalismus die Möglichkeit, ein gesundes Staatswesen aufzubauen, indem wir uns von den ewig unruhigen und militaristischen Elementen der altpreußischen und zentraldeutschen Provinzen trennen. Diese Trennung würde unsere Wiedereingliederung in die zivilisierte Welt wesentlich erleichtem. Vom volkhaften Standpunkt aus gesehen wäre Separatismus heute nicht Verrat. Wir könnten die wirklichen Grundlagen rheinischer Volkskultur stärken und die Bande mit den abgesplitterten Brücken im Westen neu knüpfen - ohne Gefahr eines Revanchekrieges. Die rheinische Freiheit würde endlich zu einer wichtigen Vorstufe zur europäischen Föderation, wenn man sie nicht als Selbstzweck, sondern als Mittel zum Zweck auffaßte. Die Aufrechterhaltung des preußischen Zentralismus drohte dagegen unsere rheinische Eigenart im Kern zu treffen und alle Brücken nach Westen definitiv abzuschneiden. Die Ansiedlung von 12 Millionen Preußen in West- und Süddeutschland wäre die end-

78 An Paul Egon Hübinger schrieb Ewig am 20. Mai 1939 und beendete den Brief mit folgenden Worten: "Datum Berolini die XIII ${ }^{\circ}$ a. Kal. Junii, sede imperiali vacante anno CXXXIII " ("Gegeben zu Berlin, am 13. Tag vor den Kalenden des Juni im 133. Jahr, seitdem der Kaiserthron vakant ist «); Privatpapiere Eugen Ewig.

79 Eugen Ewig an Raymond Schmittlein, 4.11.1945; AOFAA, AC 63/2.

${ }^{80}$ Eugen Ewig an Robert Schuman, 21.11.1945; ARS, RS 25. 
gültige Katastrophe für uns alle. Ihre volkspolitischen Auswirkungen wären noch erheblich verhängnisvoller als ihre wirtschaftlichen Konsequenzen ${ }^{81}$.

In dieser pessimistischen Schlußfolgerung kommt zweifellos der über viele Jahrzehnte für Deutschland so typische konfessionelle Gegensatz zum Ausdruck, in dem die Katholiken seit der Reichseinigung stärker noch als zuvor aus einer Minderheitenposition agiert hatten. Der von Ewig erstrebte Rheinstaat war somit auch als Bollwerk gegen ein wiederum vom preußischen Protestantismus dominierten Deutschland gedacht. Aus dieser Aversion gegen einen Zentralstaat heraus wollte er allerhöchstens einen $»$ deutschen Föderativstaat mit weitgehender Freiheit der Gliedstaaten« akzeptieren; bei einer Rückkehr zur Weimarer Republik gedachte er jedoch, sich in Österreich oder Frankreich "naturalisieren « zu lassen. Herzensangelegenheit blieb ein Rheinlandstaat, wie er in einem 1946 erschienenen Beitrag in dem Buch »Le Rhin. Nil de l'Occident« betonte:

Pour devenir un centre de rayonnement européen, la Rhénanie ne doit pas nécessairement couper tous les liens politiques avec l'Allemagne. Elle pourrait faire partie à la fois d'une confédération occidentale et d'une confédération allemande après une délimitation judicieuse des droits mutuels. Dans l'histoire du Saint Empire, cette solution n'est pas sans précédant. Quoi qu'il en soit - l'autonomie rhénane est à la fois nécessaire pour le bien de la province, pour l'avenir de l'Allemagne et pour la solidarité européenne ${ }^{82}$.

Diese Zeilen erschienen in einem Sammelband, den wohl der französische Historiker Graf Jean de Pange initiiert hatte. Er übte in der Nachkriegszeit einen nicht unerheblichen Einfluß auf Ewig aus ${ }^{83}$ und sprach sich genauso wie dieser für eine "Fédération de l'Occident« aus: »ll faut y introduire le régime fédéraliste qui dévalorise les frontières et porte atteinte à la notion de souveraineté absolue. C'est en somme le régime institué par les traités de Westphalie ${ }^{84}$. Er gehörte zu den Befürwortern eines Europas der dritten Kraft zwischen den Supermächten und teilte mit Ewig die Überzeugung, daß nationale Grenzen einer überkommenen Zeit angehören. Nicht nur wegen dieser Interessenübereinkunft schätzte de Pange den jungen Bonner Mediävisten, wie er Schuman anvertraute: $»[l$ est admirablement qualifié pour exprimer les vœux des Rhénans et indiquer les moyens de les satisfaire ${ }^{85}$. Bereits am 16. März 1947 hatte de Pange Schuman auf die Mittlerfähigkeiten von Ewig aufmerksam gemacht: »Personne n'est mieux préparé à vous seconder dans cette tâche auch die folgenden Zitate.

82

83

Eugen Ewig an Robert Schuman, 28.11.1945; ARS, RS 25.

${ }^{84}$ Jean de PANGe, Vue sur l'histoire de la Rhénanie, in: DUMONT (Hg.), Le Rhin (wie Anm. 74), S. 37-56, hier S. 52.

85 Jean de Pange an Robert Schuman, 1.3.1948; ARS, RS 28. 
[rétablir les contacts avec nos amis catholiques allemands] que $\mathrm{M}$. Ewig, dont vous avez pu apprécier à Metz la générosité et le dévouement « ${ }^{86}$.

Über de Pange erhielt Ewig auch Kontakt zu Raymond Schmittlein, Leiter der Kulturabteilung bei der französischen Militärregierung, der von dem Grafen bereits vor dem ersten Zusammentreffen ein klares Bild des ehemaligen Metzer Archivaren erhalten hatte:

Il veut réveiller dans la jeunesse allemande la tradition libérale et humanitaire qui est essentiellement fédéraliste [...]. Il s'attachera à démontrer que la Prusse a méconnu le caractère chrétien et universel de l'Empire du Moyen Âge qui nous a légué l'idée fédéraliste. L'histoire rhénane fera renaître les traditions indigènes que la Prusse voulait détruire et préparera les esprits à la Fédération de l'Occident ${ }^{87}$.

Das Zusammentreffen mit Schmittlein fiel in eine Zeit, als Ewig erste Gedanken über eine berufliche Neuorientierung anstellte. Archivar wollte er nicht bleiben, durch seine Mitarbeit bei der französischen Revue "Temps Présent" und bei der rheinischen Zeitschrift "Die Bewegung « hatte er erste Eindrücke von einer freien schriftstellerischen Tätigkeit erhalten, doch auf der Prioritätenliste stand die universitäre Laufbahn an erster Stelle. Dabei verlor er die Habilitation nicht aus dem Auge, um »später an eine österreichische Universität $\mathrm{zu}$ gehen ${ }^{88}$. Seine immer engeren Kontakte zur französischen Besatzungsmacht machten eine Verwendung in der Besatzungszone jedoch wahrscheinlicher. Ende 1945 ging Ewig dann auch davon aus, schon bald in BadenBaden zu arbeiten. Schmittlein hatte ihm einen Lehrstuhl für Regionalgeschichte an der noch zu gründenden »université rhénane« und die Redaktion eines Schulgeschichtsbuches angeboten ${ }^{89}$. Hübinger berichtete er am 1. März 1946, daß die Französische Militärregierung in Baden-Baden, die zu dieser Zeit noch nicht die Pläne zur Abtrennung des Rheinlandes aufgegeben hatte, ihn beauftragt habe, ein provisorisches historisches Schulbuch für die nordfranzösische Zone zu verfassen - »rein landesgeschichtlich (Rheinland, Rheinhessen, Pfalz)«. Das Manuskript dieser »Histoire rhénane« konnte Ewig Schmittlein im April 1946 vorlegen, der auf der Rückseite einige Anmerkungen machte, mit der Arbeit jedoch sehr zufrieden war ${ }^{90}$.

Von diesen verschiedenen Projekten hatte Ewig bereits in seinen Weihnachtsgrüßen des Jahres 1945 Robert Schuman berichtet, genauso wie von der auf Vermittlung des französischen Germanisten Robert Minder und von Henri Jourdan ${ }^{11}$, Anfang der 1930er Jahre Lektor an der Universität Bonn und Curti-

86 Jean de Pange an Robert Schuman, 16.3.1947; ibid.

87 Jean de Pange an Raymond Schmittlein, 12.11.1945; AOFAA, AC 63/2.

88 Eugen Ewig an Paul Egon Hübinger, 27.7.1945; UA Bonn, NL Hübinger, Bd. 92.

${ }^{89}$ Raymond Schmittlein an Eugen Ewig, 10.12.1945; Privatpapiere Eugen Ewig.

90 Raymond Schmittlein an Eugen Ewig, 11.6.1946; ibid.

9 Vgl. Emst-Robert CURTIUS, Balzac, traduit par Henri JOURDAN, Paris, Grasset, 1933; vgl. zu Henri Jourdan die zahlreichen Hinweise in: Dieter TIEMANN, Deutschfranzösische Jugendbeziehungen der Zwischenkriegszeit, Bonn 1989. 
us-Übersetzer, zustande gekommenen Lektorenstelle an der Universität Nancy, die er im Januar 1946 antrat und bis 1949 innehatte: "Il me serait ainsi possible de travailler en Rhénanie en gardant le contact avec la France. $\mathrm{Ce}$ changement merveilleux de la fortune personnelle m'est gage d'un meilleur avenir de nos pays «" ${ }^{22}$. Er wurde damit der erste deutsche Historiker, »der nach dem Zweiten Weltkrieg einen Lehrauftrag an einer französischen Universität erhielt ${ }^{93}$. In Nancy traf er auch mit Jean Schneider zusammen, der dort seit 1943 Professor war und während der deutschen Besatzung von der Gestapo festgenommen worden war, um ihn daraufhin in die Konzentrationslager Natzweiler-Struthof und Dachau zu deportieren.

Im Februar 1946 wurde Ewig von den französischen Behörden ein Passeport ausgestellt, so daß er nun ohne Probleme zwischen Metz, Nancy und Mainz hin- und herreisen konnte, wo er wiederum der erste Historiker war ${ }^{94}$, dem eine Stelle an der - auf französische Initiative hin - neugegründeten Universität Mainz angeboten wurde. Die französische Besatzungsmacht hatte dem inzwischen zum Gründungsrektor ernannten Josef Schmid eine vorläufige Liste als Arbeitsgrundlage zur Verfügung gestellt, so daß dieser - nach einem Besuch bei Schmittlein in Baden-Baden - Kontakt zu ihm aufnahm ${ }^{95}$ und ihm am 26. April 1946 mitteilen konnte, "daß Ihre Berufung durch die maßgebenden Dienststellen genehmigt wurde ${ }^{96}$. Nachdem die Universität am 22. Mai 1946 feierlich eröffnet worden war, begann der Unterricht am folgenden Tag auch für den Oberassistenten Eugen Ewig, der anfangs insbesondere Veranstaltungen zur Landesgeschichte des Niederrheins und zu den historischen Hilfswissenschaften abhielt.

Seine engen Beziehungen zu Vertretern der Militärregierung hatten ihm zudem bei der Stellenbesetzung an der neuen Hochschule maßgeblichen Einfluß verliehen, wie ein Brief an Hübinger dokumentiert:

Ich habe Dich, Büttner und Schieffer für eine ordentliche Professur vorgeschlagen. Man hat mich gebeten, die Verbindung mit Euch aufzunehmen [...]. Falls Du Dich für Mainz interessierst, kannst Du Dich an mich oder auch direkt nach Baden-Baden wenden (Direction de l'Éducation Publique, Hôtel Stéphanie). Dasselbe gilt für Schieffer. Ich würde mich unbändig freuen, wenn wir dort zusammen arbeiten könnten. Directeur de l'Éducation Publique est le général Schmittlein. Du kannst Dich an ihn oder über ihn an Magnifizenz wenden mit

Eugen Ewig an Robert Schuman, 23.12.1945; ARS, RS 25.

${ }^{93}$ Rudolf SCHIEFFER, Konkrete Spätantike. Vermittler seiner Zeit: Zum Tod des Historikers Eugen Ewig, in: FAZ, 3.3.2006.

94 Vgl. Katja WOJTYNOWSKI, Das Fach Geschichte an der Johannes Gutenberg-Universität Mainz 1946-1961, Stuttgart 2006, S. 16

95 Josef Schmid an Eugen Ewig, 29.3.1946; Privatpapiere Eugen Ewig.

96 Josef Schmid an Eugen Ewig, 26.4.1946; ibid. Bei den Dienststellen handelte es sich um den Oberregierungspräsidenten Hessen-Pfalz und den Directeur de l'Éducation publique der französischen Militärregierung. 
Berufung auf die Unterredung, die ich mit Magnifizenz gehabt habe. Schmittlein ist ein Freund von Jean de Pange, dem ich diese Beziehung verdanke ${ }^{97}$.

Es war also nicht das von Heinrich Appelt bemühte »Schicksal«, das Schieffer wie auch Büttner als außerplanmäßige Professoren nach Mainz führte ${ }^{98}$, sondern neben ihrer wissenschaftlichen Beschäftigung mit Themen der rheinischen Geschichte sowie mit Problemen der europäischen Geistes- und Kulturgeschichte ein früh angelegtes Netzwerk bzw. "Denkkollektiv« (Ludwig Fleck). Durch ihre Verbundenheit zum Rheinland bzw. zu Bonn und ihre gemeinsamen Erfahrungen in den Archiven Deutschlands und Frankreichs hatten sie sich nie aus den Augen verloren, so daß das Netzwerk nach Kriegsende schnell wieder verdichtet und das Historische Seminar der Universität Mainz zu einer Hochburg katholisch-abendländischer Historiker werden konnte ${ }^{99}$. Während an den traditionellen deutschen Hochschulen nur wenig personelle Veränderungen $\mathrm{zu}$ beobachten gewesen waren, bot die Universität in Mainz gerade der Privatdozentengeneration deutlich bessere Möglichkeiten und entwickelte sich für diese zu einem wissenschaftlichen Sprungbrett. Büttner erhielt bereits 1949 eine ordentliche Professur in Marburg; genauso wie Schieffer 1951 in Mainz, bevor er 1954 einem Ruf nach Köln folgte, so daß Ewig, der sich 1952 mit einer Studie über »Trier im Merowingerreich« bei Leo Just habilitiert hatte ${ }^{100}$, im Jahre 1954 sein Nachfolger als Ordinarius für mittelalterliche Geschichte und historische Hilfswissenschaften an der Universität Mainz werden konnte ${ }^{101}$.

Die »französische« Universität Mainz erlaubte es ihm darüber hinaus, das Beziehungsnetz mit seinen Freunden in Frankreich weiter zu pflegen und auszubauen. Anläßlich des 10. Geburtstages ihrer Wiedergründung im Jahre 1956 sagte Ewig: "Calquée sur le modèle de ses sœurs allemandes, réouverte [sic!] avec l'aide de la France, l'université de Mayence se doit de constituer un pont entre les deux pays ${ }^{102}$. Durch seine Teilnahme an den von Raymond Schmitt-

97 Eugen Ewig an Paul Egon Hübinger, 1.3.1946; UA Bonn, NL Hübinger, Bd. 2.

98 Heinrich APPELT, Theodor Schieffer, in: Deutsches Archiv für Erforschung des Mittelalters 48 (1992), S. 417-419.

99 Vgl. die Listen der Professoren, Dozenten und Assistenten der Universität Mainz in: MAE/Colmar, AOFAA, AC 197/2. Nach seinem Besuch im Mainzer Rektorenamt schrieb Theodor Schieffer an Heinrich Büttner am 7.4.1946: »Ich hätte beinahe laut aufgelacht über die automatische Sicherheit, mit der unsere Wege unter den unwahrscheinlichsten Voraussetzungen sich immer wieder berühren«; zit. nach WOJTYNOWSKI, Das Fach Geschichte (wie Anm. 95), S. 24.

${ }^{100}$ Vgl. Eugen EwIG, Trier im Merowingerreich. Civitas, Stadt, Bistum, Trier 1954.

${ }^{101}$ Ewig war im Jahre 1948 ein Lehrstuhl an der Universität des Saarlandes angeboten worden, den er jedoch abgelehnt hatte. Der verantwortliche Regierungsrat im Saarbrücker Ministerium für Kultus, Unterricht und Volksbildung schrieb ihm daraufhin am 7.7.1948 (Privatpapiere Eugen Ewig): "Die Entschiedenheit mit der Sie den Lehrstuhl ablehnen ist für Sie vielleicht ehrenvoller als dieser Lehrstuhl«.

${ }^{102}$ Rede von Eugen Ewig in französischer Sprache [1956]; ibid. 
lein initiierten Internationalen Historikertreffen in Speyer zwischen 1948 und 1950 engagierte er sich darüber hinaus maßgeblich für die Rückkehr der (west-)deutschen Historiker in den Kreis der internationalen Historikerzunft $^{103}$. Diese »Institution von eigenartig privatem oder zumindest nur unauffällig offiziellem Charakter" verfolgte das Ziel, die nationalen Geschichtsschreibungen und Schulgeschichtsbücher einer intensiven Überprüfung zu unterziehen, um die unterschiedlichen Geschichtsbilder einander anzugleichen und über diesen Weg einen vielschichtigen Umerziehungs- und Annäherungsprozeß zwischen ehemaligen Kriegsgegnern auf zivilgesellschaftlicher Ebene einzuleiten ${ }^{104}$. Ewig gehörte damit zu den Mitbegründern des sogenannten "Esprit de Spire«, mit dem der "Geist internationaler und insbesondere deutsch-französischer Verständigung auf dem Grunde der Gemeinsamkeit wissenschaftlicher Gesinnung " beschworen wurde ${ }^{105}$. Als Mitarbeiter von Schulgeschichtsbüchern beteiligte er sich im folgenden daran, diesem "Esprit« Dauerhaftigkeit zu verleihen ${ }^{106}$.

Institutionalisierte Dialogstrukturen wie die Treffen in Speyer förderten zum einen die Neukonfiguration der Netzwerke des Wissens und der Wissenschaft im europäischen Kontext; zum anderen leisteten sie über »die Koordinierung des abendländischen Geschichtsbildes « $~{ }^{107}$ einen Beitrag zu der Imaginierung eines neuen gemeinsamen Raumes bzw. zu einem Prozeß, den Karl Schlögel als "Remapping « bezeichnet ${ }^{108}$. Durch die Infragestellung einer Vielzahl von Werten und Einstellungen, aber auch von bisher vertrauten Räumen begannen sich genauso die »Karten in den Köpfen « zu wandeln. An diesen mentalen Transformationsprozessen beteiligten sich auch die Historiker auf unterschiedliche Weise und mit verschiedenen Inhalten ${ }^{109}$. Es kann als Kontinuität im Denken von Eugen Ewig gewertet werden, daß er bei der Suche nach dem alternativen Ort der deutschen Nation über die nationalen Grenzen hinausschaute und mit einer kulturell-weltanschaulichen Argumentation eine historiographische Westverschiebung des preußenlastigen Deutschland-

${ }^{103}$ Ewigs Teilnahme am I. (wie u.a. Ritter, Schnabel und Ramackers) und III. Internationalen Historikertreffen in Speyer (wie u.a. Büttner, Heimpel, Hübinger, Schieffer, Tellenbach) ist in den Quellen belegt; vgl. MAE/Colmar, AC 262 (1) und 275 (1).

${ }^{104} \mathrm{Vgl}$. Christoph CORNELISSEN, Gerhard Ritter. Geschichtswissenschaft und Politik im 20. Jahrhundert, Düsseldorf 2001, S. 470ff.

${ }^{105}$ H.W. ERBE, Internationales Historikertreffen in Speyer, in: GWU 1 (1950), S. $301 \mathrm{f}$.

${ }^{106}$ In der Serie »Erbe des Abendlandes« übernahm Ewig gemeinsam mit dem Gymnasiallehrer Robert Frohn einen Band, der vom "Sacrum Imperium des Abendlandes" bis zum "Zeitalter des Absolutismus" reichte; Erbe des Abendlandes. Lehrbuch der Geschichte für höhere Schulen, Teil II: Das Abendland, Düsseldorf 1954.

${ }^{107}$ Dritter Internationaler Historikerkongreß vom 17.-20. Oktober 1949, in: GWU 1 (1950) 1, S. 52.

${ }^{108}$ Vgl. Karl SCHLÖGEL, Die Mitte liegt ostwärts, München 2002, S. $248 \mathrm{ff}$.

${ }^{109}$ Sebastian CONRAD, Auf der Suche nach der verlorenen Nation. Geschichtsschreibung in Westdeutschland und Japan 1945-1960, Göttingen 1999, S. 360. 
bildes einforderte. In Anlehnung an Hermann Platz und aus einem weiterhin bestehenden antipreußischen Affekt heraus formulierte er eine rheinische „Kernlandtheorie«, indem er die europäischen Gemeinsamkeiten in die karolingische Vergangenheit zurückprojizierte und für das Rheinland eine geschichtlich wichtige, schicksalhafte Aufgabe reklamierte: "Nicht zufällig ist der Schwerpunkt unseres Lebens gerade in einer Zeit, die zur europäischen Einheit strebt, wieder an den Rhein gerückt. Damit ist eine wichtige Voraussetzung für die Sendung des rheinischen Deutschland gegeben « ${ }^{110}$. Den kontingenten Begriff »Europa « fülite er mit »Abendland" und ordnete auf diese Weise den Nationsbegriff in die christlich-abendländische Wertegemeinschaft ein, um Deutschland den Sprung in einen übergreifenden Kulturraum zu ermöglichen. Diesen Aufsatz hatte Ewig dem Bundeskanzler zukommen lassen und in seinem vertraulichen Schreiben nochmals auf die Bedeutung einer abendländischen Geschichtsforschung hingewiesen:

Der Wert der Arbeit dieser und anderer Gelehrter liegt darin, daß sozusagen von innen her, ohne unnütze Diskussionen über die jüngere nationalsozialistische oder die vorhergehende preußische Epoche ein neues Geschichtsbewußtsein geprägt wird. Daß dieser Arbeit aber damit auch eine eminent politische Bedeutung zukommt, liegt auf der Hand [...]. Der Bund wird nach meiner Meinung die Zukunft gewinnen, wenn es ihm gelingt, ein neues Nationalbewußtsein zu prägen, das von vornherein in die europäische Ganzheit eingebettet ist. Das westdeutsche Volk fühlt dies sehr wohl, wenn es sich auch von sich aus von den überkommenen Anschauungen nicht befreien vermag. Der Weg, der aus dem Dilemma führt, ist aber, wie gesagt, bereits von einer Reihe von Forschern beschritten. Es liegt auch im Interesse des Bundes, diesen positiven Kräften die Bahn frei zu machen "'].

Ewigs Ausführungen deuten auf ein dialektisches Verhältnis von historisch unterlegten Raumdiskursen und politischer Neuorientierung hin, das die Bonner Politik der Westintegration und die deutsch-französische Verständigung historisch flankierte. Thesenartig kann hier formuliert werden, daß der Kanzler das räumliche Konstrukt des Okzidents bzw. des Westens brauchte, so wie der Diskurs über die Geschichte des Abendlandes ohne die Westintegration der Bundesrepublik nicht zu denken ist.

\section{Mittler zwischen deutscher und französischer Historie}

Wer Eugen Ewig in späteren Jahren kennenlernte, mag sich nur schwerlich vorstellen, wie auch ihn Krieg und Nachkriegszeit politisiert hatten. Neben den Zeitumständen mögen dazu auch die persönlichen Kontakte zu Robert

${ }^{110}$ Eugen EwIG, Landschaft und Stamm in der deutschen Geschichte, in: GWU 1 (1950), S. $154-168$.

${ }^{11}$ Eugen Ewig an Konrad Adenauer, 5.9.1950; Privatpapiere Eugen Ewig. 
Schuman und Konrad Adenauer beigetragen haben, zwischen denen er sich als "Postillon « betätigte ${ }^{1 / 2}$. Der direkte Kontakt zum Bundeskanzler läßt sich ab Ende der 1940er Jahre nachweisen ${ }^{13}$; die enge Beziehung zu Schuman war seit der Metzer Zeit nie abgebrochen. Bei einem Essen mit dem französischen Außenminister am 22. April 1950 in Paris bemühte sich Ewig dabei, mögliche "Voreingenommenheiten« auf französischer Seite gegenüber Adenauer auszuräumen. Mit diesem Bestreben rannte er bei Schuman jedoch offene Türen ein, der die whohen moralischen Qualitäten « des Kanzlers betonte und ihn als die beste Lösung für die Bundesrepublik und das europäische Interesse bezeichnete, wie Adenauers Leibarzt und zukünftiger Schwiegervater von Ewig, Paul Martini, dem Kanzler am 10. Mai 1950, also am Tag nach der Verkündung des Schuman-Plans mitteilte ${ }^{114}$.

Die Wertschätzung, die Ewig im Kanzleramt zuteil wurde, dokumentiert auch das Angebot des damaligen Ministerialdirektoren im Bundeskanzleramt und späteren Botschafters in Paris Herbert Blankenhorn, der Ewig am 4. September 1950 vorschlug ${ }^{15}$, wals Angestellter mit dem Gehalt eines Oberregierungsrats für 6 Monate das Amt eines Kulturreferenten beim deutschen Generalkonsulat in Paris « wahrzunehmen ${ }^{116}$. Obgleich er zu dem Entschluß kam, »daß eine kurz befristete Tätigkeit in Paris weder der deutschen Sache förderlich noch vor meiner Familie und der Mainzer Universität vertretbar« sei $^{117}$, vergaß Adenauer Ewigs enge Verbindungen nach Frankreich nicht und ließ ihn in Person von Blankenhorn wissen, "daß er Sie gern von Fall zu Fall zu Missionen nach Paris berufen wird, die einen besonders vertraulichen Charakter besitzen ${ }^{118}$. Die Überlegungen, den damals 37jährigen Ewig mit politischen Aufgaben zu betrauen, kamen nicht von ungefähr, verstand er sich doch

112 Ich danke Herrn Prof. Dr. Vincent Berning für diese Information vom 27.11.2004.

${ }^{113}$ Am 5.5.1949 übersandte das Büro des damals als Präsident des Parlamentarischen Rates fungierende Adenauer folgendes Schreiben an Ewig (Privatpapiere Eugen Ewig): „Sehr geehrter Herr Dr. Ewig! Präsident Dr. Adenauer bittet Sie, morgen vormittags $1 / 211 \mathrm{Uhr}$ zu ihm in den Parlamentarischen Rat zu kommen

114 Paul Martini an Konrad Adenauer, 10.5.1950; ibid.

${ }^{115}$ In einem Schreiben von André François-Poncet für Robert Schuman vom 16.5.1950 teilt dieser dem französischen Außenminister mit, daß Adenauer ihm seine Absicht mitgeteilt habe, Eugen Ewig mit einem noch zu definierenden Posten an das Generalkonsulat nach Paris zu entsenden. Vor dieser Entscheidung wünsche er jedoch die Meinung von Schuman (André François-Poncet an Robert Schuman, 10.5.1950; MAE/Paris, Europe, Allemagne, 1944-1970, Bd. 143, Bl. 36). Über den französischen Botschafter in London, René Massigli, ließ Schuman ausrichten, daß er eine solche Entscheidung begrüße (René Massigli an Ministère des Affaires étrangères, 18.5.1950; ibid.).

${ }^{116}$ Vgl. zum politischen Kontext: Frank-Lothar KROLL, Deutschlands Weg nach Europa. Der Wiederaufbau des Auswärtigen Dienstes und die Errichtung deutscher Generalkonsulate in Paris und London 1950, in: Historische Mitteilungen der Ranke-Gesellschaft 3 (1990), S. 161-180.

${ }^{117}$ Eugen Ewig an Konrad Adenauer, 5.9.1950; Privatpapiere Eugen Ewig.

${ }^{118}$ Herbert Blankenhorn an Eugen Ewig, 5.10.1950; ibid. 
in den Nachkriegsjahren selber als Historiker mit politischen Ambitionen, wie aus seinem »vertraulichen« Schreiben vom 5. September 1950 hervorgeht. Er skizzierte hier ein historisches Forschungsprojekt zum besseren "Verständnis der europäischen Vergangenheit«:

Ziel wäre ein vom Rhein her geprägtes neues deutsches und europäisches Bewußtsein. Diese Arbeit müßte ihren Ausgang vom Mittelalter nehmen, weil hier einerseits die Anfänge des Abendlandes liegen und andererseits der zeitliche Abstand einer ruhigen Betrachtung besonders förderlich ist ${ }^{119}$.

Aus den weiteren Darlegungen wird zudem deutlich, daß Ewig sich innerlich noch nicht gänzlich von der Idee verabschiedet hatte, den Posten des Kulturreferenten zu übernehmen, doch zum einen mußte ihm diese Stelle eine langfristige materielle Absicherung bieten, zum anderen schwebte ihm eine Funktion an der Schnittstelle von Diplomatie und Wissenschaft vor:

Ein Pariser Kulturreferent, der einige Muße zu wissenschaftlicher Arbeit hätte, könnte ohne jedes Aufsehen sowohl den Kontakt zwischen den aufgeschlossenen Kreisen hüben und drüben herstellen, wie auch selbst in Verbindung mit dem Kreis westdeutscher Universitätslehrer die notwendigen Forschungen in die Wege leiten. Frankreich ist für diesen Zweck der wichtigste Ansatzpunkt, weil die deutsch-französischen Kulturbeziehungen für die Werdeund erste Blütezeit des Abendlandes weitaus am bedeutsamsten waren. In einigen Jahren wäre ein festes wissenschaftliches Fundament gelegt, das auch die widerstrebenden oder zögernden Kreise nicht mehr übersehen könnten.

Sind diese Pläne als Urzelle für die acht Jahre später gegründete deutsche historische Forschungsstelle zu verstehen? Mehr als Vermutungen können hier nicht angestellt werden. Dafür finden wir Bestätigung, daß das Bundeskanzleramt die Funktion des Kulturreferenten nicht wie Ewig definieren wollte: "Eine Verbindung beider Dinge, diplomatische Tätigkeit und wissenschaftliche Forschung, ist auf Dauer nicht möglich, da entweder das eine oder das andere darunter zu stark leiden würde ${ }^{120}$.

119 Eugen Ewig richtete am 5.9.1950 zwei Briefe an Konrad Adenauer; in dem oben zitierten begründete er seine Ablehnung, die Stelle eines Kulturreferenten in Paris anzunehmen, in dem zweiten vertraulichen Schreiben legte er sein Forschungsvorhaben dar (ibid). Ewigs Plädoyer für das Mittelalter als Ausgangspunkt für ein historisches Forschungsprojekt kann zweifellos als sblauäugig bezeichnet werden, hatte doch gerade der Nationalsozialismus diese Epoche wie kein anderes Regime in Deutschland zuvor legitimiert und ihr weine neue, völkische Bedeutung" gegeben (Oded HEILBRONNER, "[...] aber das /Reich lebt in uns". Katholische Historiker unter dem Nationalsozialismus, in: Tel Aviver Jahrbuch für deutsche Geschichte XXV [1996], S. 219-231, hier S. 230). Karen Schönwalder weist in diesem Zusammenhang darauf hin, daß sich der »Sachsenschlächter" Karl der Große in den letzten Kriegsjahren vom Saulus zum Paulus entwickelte, instrumentalisierten ihn die $\mathrm{Na}$ tionalsozialisten doch nun angesichts des Vordringens der Roten Armee im Osten als Wegbereiter einer abendländischen Europaidee, mit der sich das »Dritte Reich « als letztes Bollwerk gegen den anstürmenden Bolschewismus zu profilieren gedachte; Karen SCHÖNWALDER, 'Taking Their Place in the Front-liner(?): German Historians during Nazisme and War, in: ibid., S. 205-217, hier S. $215 \mathrm{f}$

${ }^{120}$ Herbert Blankenhom an Eugen Ewig, 5.10.1950; Privatpapiere Eugen Ewig. 
Eine Institutionalisierung der deutsch-französischen Historikerbeziehungen in Form einer deutschen Forschungsstelle in Paris trat folglich wieder in den Hintergrund, blieb jedoch weiterhin ein Projekt von Eugen Ewig, wie aus seiner Notiz für Konrad Adenauer vom Sommer $1952 \mathrm{zu}$ entnehmen ist, in der wie bereits 1950 die "politisch-psychologischen« vor den fachlichen Gesichtspunkten standen: "Von den gemeinsamen Grundlagen der Geschichte beider Völker her ist der Kontakt am leichtesten zu finden und gegebenenfalls ein gemeinsames Geschichtsbild am besten zu erarbeiten. Die nationale Empfindlichkeit kann durch eine solche Arbeit nicht erregt werden « ${ }^{12 !}$.

Hinter diesen Ausführungen verbarg sich die Idee, die Gründung einer historischen Forschungsstelle in die laufenden Verhandlungen über ein deutschfranzösisches Kulturabkommen aufzunehmen und nach Möglichkeit im Vertragstext zu fixieren ${ }^{122}$. Wie Rudolf Salat, Leiter der Kulturabteilung im AA, Ewig jedoch Ende 1952 mitteilte, war an eine solche Regelung nicht zu denken, gehörte es doch nicht zu den Usancen von Kulturabkommen, konkrete Projekte in den Vertragstext aufzunehmen ${ }^{123}$. Eine schnelle Verwirklichung des Projektes erschien somit illusorisch, wie Ewig in einem Schreiben an Salat vom 27. März 1953 befürchtete ${ }^{124}$, doch ließ sich der Mainzer Historiker von der zurückhaltenden Reaktion der Kulturabteilung des AA nicht abschrecken. Er präzisierte nunmehr seine Pläne und sprach sich für ein »zweiseitiges Projekt« und »die Bildung eines Teams mittelalterlicher Historiker« aus, um sowohl in Frankreich ein deutsches und in der Bundesrepublik ein französisches historisches Institut zu gründen. Selbst aus heutiger Sicht erscheint es visionär, daß Ewig bereits 1952 eine integrierte Form der Zusammenarbeit anstrebte:

Die beiderseitigen Forschungsstellen würden unter der Aufsicht je eines Beirats von Ordinarien beider Länder arbeiten, die an dem Projekt persönlich oder amtlich interessiert wären [...]. Die Beiräte müßten das Programm für die Forschungsstellen entwerfen und in regelmäßigen Abständen zusammentreten. Eine Fusionierung zu einem regelrechten Team wäre ins Auge zu fassen ${ }^{125}$.

Am 20. Mai sprach er mit Henry Spitzmuller, Nachfolger von Raymond Schmittlein an der Spitze der Direction générale des Affaires culturelles, der auf seine Pläne durchaus positiv reagierte und bei den entscheidenden Stellen vorsichtig sondieren wollte. Zugleich wandte sich Ewig im Mai brieflich an Robert Schuman, „um ihn über das Projekt zu orientieren«. Von bundesdeutscher Seite war für den Moment jedoch wenig politische Unterstützung zu erwarten, standen am 6. September 1953 doch Bundestagswahlen an ${ }^{126}$.

${ }^{121}$ Notiz von Eugen Ewig für Konrad Adenauer [Sommer 1952]; ibid.

${ }^{122}$ Walter Hallstein an Eugen Ewig, 23.12.1952; ibid.

${ }^{123}$ Rudolf Salat an Eugen Ewig, 30.12.1952; ibid.

${ }^{124}$ Eugen Ewig an Rudolf Salat, 27.3.1953; ibid.

125 Eugen Ewig an Rudolf Salat, 21.5.1953; ibid. Hier auch das folgende Zitat.

${ }^{126}$ Rudolf Salat an Eugen Ewig, 5.8.1953; ibid. 
Eine neue Gelegenheit ergab sich erst, als Adenauer Anfang 1954 gegenüber Vertretern der westdeutschen Geschichtswissenschaft verlauten ließ, aus dem seiner Bewirtschaftung vorbehaltenen Teil des Forschungsfonds geschichtswissenschaftliche Vorhaben unterstützen zu wollen. Neben drei weiteren Historikern ließ auch Heinrich Büttner »auf Anregung und nach Rücksprache mit Herrn Ewig« »Vorschläge über historische Forschungsaufgaben« dem Kanzleramt zukommen, die sich aus sechs Unterprojekten zusammensetzten. Die Themenwahl war nicht nur wissenschaftlich begründet, sondern entsprach zugleich jenen abendländischen Tendenzen, die so typisch für die erste Hälfte der Ära Adenauer waren:

Das Reich der Karolinger ist für West- wie Ostfranken, für französische wie deutsche Geschichte, die gemeinsame Ausgangsbasis. Die geistigen und religiösen Strömungen, die verfassungsmäßigen Einrichtungen und die wirtschaftlichen Entwicklungen können in ihren letzten Zusammenhängen nur durch eine überregionale Betrachtung zutiefst erfaßt werden. Die Beziehungen und Spannungsfelder der romanisch-germanischen Welt spielen dabei eine wichtige Rolle ${ }^{127}$.

Büttner hatte den einzelnen Projekten bereits verschiedene Namen von Historikern (Ewig, Heimpel, Hübinger, Schieffer, Steinbach, Tellenbach) zugeordnet, deren Ruf nicht nur fachliche Qualität, sondern auch weltanschauliche Lauterkeit verbürgen sollte:

Die genannten Forscher beschäftigen sich nicht erst ad hoc mit jenen Problemen, die letztlich auf die gemeinsame Grundlage der abendländischen Kultur ausgerichtet sind, sondern wurden durch ihre wissenschaftliche Entwicklung sozusagen von selbst darauf gewiesen, einen möglichst weiten historischen Bereich in ihr Arbeitsfeld einzubeziehen. Daß sich die genannten Herren persönlich der gemeinsamen christlichen Grundlage verpflichtet fühlen, ist wohl kein Zufall ${ }^{128}$.

Als im Kanzleramt die eingegangenen Projektanträge im Dezember 1954 zwischen Ministerialbeamten und Historikern diskutiert wurden ${ }^{129}$, herrschte Einigkeit unter den Teilnehmern, die vom Bundeskanzler in Aussicht gestellten Mittel nicht für die eingereichten Projekte zu verwenden, sondern eher einen »lang gehegten Wunsch der deutschen Historiker ${ }^{130}$ zu erfüllen: eine Deutsche Historische Forschungsstation in Paris ${ }^{13 !}$. $"$ Die geistige Leitung, die Aufsicht über die Verwaltung, die Vertretung nach außen und die Verantwortung gegenüber dem Kostenträger« sollte ein namhafter deutscher Historiker übernehmen. Ewigs vielfältige Kontakte nach Frankreich bewogen seinen langjäh-

${ }^{127}$ Vorschläge über historische Forschungsaufgaben [Februar 1954]; BAK, B 136, Bd. 912, B1. 261.

${ }^{128}$ Heinrich Büttner an Paul Martini, 21.2.1954; BAK, B 136, Bd. 912, B1. 260.

${ }^{129} \mathrm{Vgl}$. Zusammenstellung der historischen Forschungsvorhaben mit Themen und Verfassern, für die Zuschüsse beantragt worden sind [Dezember 1954]; ADHIP, Bd. 634.

${ }^{130}$ Gerd Tellenbach an Wilhelm Grau, 27.12.1954; BAK, B 136, Bd. 912, B1. 271.

${ }^{131}$ Vorlage des Referates 9 für den Staatssekretär, 27.12.1954; BAK, B 136, Bd. 912, B1. $265 \mathrm{ff}$. 
rigen Weggefährten Hübinger, seit 1. März 1954 Leiter der Abteilung III "Kulturelle Angelegenheiten des Bundes « ${ }^{132}$, bereits am 22. Dezember Fühlung zu ihm aufzunehmen. Schon am nächsten Tag informierte Hübinger das Bundeskanzleramt, daß der Mainzer Mediävist für diese Aufgabe zur Verfügung stehe:

Da das ganze Vorhaben darauf abgestellt ist, zunächst in einem ungezwungenen, fast privaten Stil anzulaufen, halte ich gerade Professor Ewig für besonders qualifiziert, um als Protektor tätig zu sein, da er wie kein anderer der sachlich in Frage kommenden Herren über das hohe $\mathrm{Ma} ß$ an persönlichen Beziehungen zu maßgebenden wissenschaftlichen und politischen Kreisen Frankreichs verfügt, das es ihm ermöglichen wird, so unoffiziell wie möglich und doch mit entsprechender Autorität aufzutreten ${ }^{133}$.

Der Freiburger Historiker Gerd Tellenbach, der selbst auch »einen günstigen Eindruck von Persönlichkeit und Leistungsfähigkeit« Ewigs besaß, hielt Rücksprache mit Hermann Aubin, dem Vorsitzenden des Verbandes Deutscher Historiker, und Friedrich Baethgen, dem Präsidenten der MGH. Aubin gab zu bedenken, daß Ewig im Zweiten Weltkrieg am Staatsarchiv in Metz gearbeitet habe. Zudem sprach gegen ihn in dieser Sondierungsphase sein junges Alter und die damit begründete mangelnde wissenschaftliche Notorietät sowie die fehlende Tradition der Universität Mainz, die sin wissenschaftlichen Kreisen noch nicht das gleiche Ansehen genieße wie andere deutsche Universitäten ${ }^{134}$. Es war nicht unerheblich, daß sich Max Braubach für Ewig einsetzte und »auf Grund einer sehr genauen Kenntnis der menschlichen und wissenschaftlichen Persönlichkeit von Herrn Ewig« sein Unverständnis über die teilweise anzutreffenden Vorbehalte zum Ausdruck brachte ${ }^{135}$. Anfang Februar 1955 wischte Hübinger die Einwände gegen Ewig endgültig vom Tisch: „Dieser habe bei seiner Tätigkeit in dem Metzer Archiv nicht gegen französische Interessen gearbeitet; im Gegenteil habe er dort für den späteren Ministerpräsidenten R. Schuman Archivmaterial sichergestellt«. In seiner doppelten Rolle als Leiter der Kulturabteilung im BMI und Historiker bot sich Hübinger nun an, die Errichtung der Forschungsstation gemeinsam mit Ewig vorzubereiten ${ }^{130}$.

Die so verheißungsvoll angelaufenen Planungen gerieten jedoch durch den negativen Bescheid der Diplomatischen Vertretung in Paris vom 16. März 1955 ins Stocken. Bei einer neuerlichen Beratung im Kanzleramt schlug Hübinger Mitte Januar 1956 vor, in privaten Besprechungen zwischen bundes-

${ }^{132} \mathrm{BMI}$ an Hübinger 16.3.1954; UA Bonn, NL Hübinger, Bd. 184.

${ }^{133}$ Paul Egon Hübinger an Wilhelm Grau, 23.12.1954; BAK, B 136, Bd. 912, Bl. 262.

${ }^{134} \mathrm{Vgl}$. Gerd Tellenbach an Wilhelm Grau, 27.12.1954; BAK, B 136, Bd. 912, Bl. $271 \mathrm{ff}$;; Vorlage des Referates 9 (Wilhelm Grau) »Betr.: Historische Forschungsstation in Paris«, März 1955; ibid., Bl. 282ff.

${ }^{135}$ Max Braubach an Wilhelm Grau, 31.12.1954; BAK, B 136, Bd. 912, B1. 275.

${ }^{136} \mathrm{Vgl}$. Vorlage des Referates 9 (Wilhelm Grau) »Betr.: Historische Forschungsstation in Paris«, März 1955; BAK, B 136, Bd. 912, Bl. $282 f f$. 
deutschen und französischen Historikern die praktischen Schritte zur Verwirklichung dieses Projektes zu erörtern. Er regte ferner an, Eugen Ewig für eine Reise nach Paris zu gewinnen, "um diese erste vorsichtige Fühlungnahme aufzunehmen $\propto{ }^{137}$. Dieser willigte umgehend ein und reiste mit Mitteln des Bundeskanzleramtes vom 26. Februar bis 17. März 1956 in die französische Hauptstadt ${ }^{138}$, wo er mit den 30 führenden Persönlichkeiten des kulturellen Lebens in Paris aus den verschiedenen Universitäten und Grandes Écoles zusammentraf sowie darüber hinaus Robert Schuman und André FrançoisPoncet (1887-1978) aufsuchte. »Kein Gesprächspartner hat irgendeinen Einwand gegen die Errichtung einer deutschen Forschungsstelle erhoben «, so Ewigs erste Schlußfolgerung, doch formulierten die französischen Historiker vor dem Hintergrund der Erfahrungen mit dem »Deutschen Institut « während der "Occupation $"{ }^{139}$ eine Grundbedingung: sie »sur base universitaire « einzurichten ${ }^{140}$. Ewig wußte, daß es bei seiner Reise nicht alleine um die Eröffnung einer wissenschaftlichen Einrichtung ging, sondern genauso um die deutschfranzösische Verständigung: "Sie [die Aussagen der französischen Historiker] zeigen aber auch, daß die Forschungsstelle eine Brücke zu den französischen Kreisen werden kann, die Deutschland bis heute noch reserviert gegenüberstehen«. Da nun auch die Bonner Diplomaten keine Einwände mehr hatten, war der Durchbruch geschafft.

Ihren wissenschaftlichen bzw. zivilgesellschaftlichen Charakter sicherten Gerd Tellenbach, Max Braubach und Eugen Ewig, indem sie am 2. April 1957 in Mainz die Wissenschaftliche Kommission zur Erforschung der Geschichte der deutsch-französischen Beziehungen als Gesellschaft des Bürgerlichen Rechts gründeten, zu der 1959 Paul Egon Hübinger nach seinem Ausscheiden aus dem BMI stie ${ }^{141}$. Die ehrenamtlichen Mitglieder wählten Eugen Ewig zum Geschäftsführer, der in den folgenden Monaten die Institutionalisierung in Verhandlungen mit den offiziellen Instanzen und besonders mit dem Bundesinnenministerium auf den Weg brachte, das die Forschungsstelle bis zu ihrer Umwandlung in ein Bundesinstitut im Jahre 1964 vollständig finanzierte.

${ }^{137}$ Vermerk über eine Besprechung im Bundeskanzleramt vom 17.1.1956, 11.00 Uhr zum Plan einer deutschen geschichtswissenschaftlichen Station in Paris, 20.1.1956; PA/AA, B 94, Bd. 615.

${ }^{138}$ Eugen Ewig an das Bundeskanzleramt, 30.1.1956; BAK, B 136, Bd. 912, Bl. 336.

139 Vgl. Eckard MiChELS, Das Deutsche Institut in Paris 1940-1944. Ein Beitrag zu den deutsch-französischen Kulturbeziehungen und zur auswärtigen Kulturpolitik des Dritten Reiches, Stuttgart 1993; Frank-Rutger HausmanN, "Auch im Krieg schweigen die Musen nicht«. Die Deutschen Wissenschaftlichen Institute im Zweiten Weltkrieg, Göttingen 2001 .

140 Bericht über meine Sondierung in Paris zwecks Errichtung einer deutschen Forschungsstelle, März 1956; BAK, B 136, Bd. 912, Bl. 353ff.

$14 !$ Vgl. Eugen EwIG, Paul Egon Hübinger (1911-1987), in: Francia 15 (1987), S. 1143 1147. 
Mit maßgeblicher Unterstützung durch Schuman und Adenauer ${ }^{142}$ konnte schließlich das Centre allemand de recherches historiques am 21. November 1958 offiziell eröffnet werden und seine Tätigkeit unter maßgeblichem Zutun der beiden ersten Mitarbeiter, Hermann Weber und Rolf Sprandel, aufnehmen. Dem 1964 in ein Bundesinstitut umgewandelten Deutschen Historischen Instituts blieb Ewig als Mitglied bzw. Vorsitzender des Wissenschaftlichen Beirats bis 1984 treu.

$\mathrm{Zu}$ seinen ersten Bemühungen, sich als Mittlerinstitution zu profilieren, gehörte die Organisation von deutsch-französischen Historikertreffen, dessen erstes 1961 in Saarbrücken stattfand und zu einem Markstein für das weitere Verhältnis der Historiker beider Länder werden sollte, wie aus dem von Ewig verfaßten Tagungsbericht hervorgeht:

In seinem Schlußwort betonte Prof. [Fernand] Braudel als Sprecher der französischen Delegation, daß die seit 1914 unterbrochenen Beziehungen zwischen der deutschen und der französischen Geschichtswissenschaft erst auf dieser Tagung wieder neu geknüpft worden seien, daß das Colloquium in jeder Hinsicht einen Neuanfang bedeute ${ }^{143}$.

\section{Fazit}

Frühe räumliche und intellektuelle Prägungen im katholisch-abendländischen Milieu des Rheinlandes hatten den Blick von Eugen Ewig bereits in frühen Jahren in Richtung Frankreich gerichtet, das ihm im Gegensatz zu nicht wenigen Vertretern der deutschen Historikerzunft in der ersten Hälfte des 20. Jahrhunderts nicht zu dem immer wieder beschworenen "Erbfeind " geworden war. Während diese mit ihren Forschungen maßgeblich zur Verbreitung dieses Bildes beigetragen hatten, erlag Ewig selbst während des »Dritten Reichs « nicht dem Anpassungsdruck. Im Gegensatz zu nicht wenigen Kollegen widersetzte er sich der Tendenz, "für das zentrale Problem des jetzigen Krieges und der bevorstehenden Neuordnung Europas das geschichtliche Rüstung beizubringen ${ }^{144}$. Vielmehr entwickelte er in dieser Zeit eine transnationale Sensibilität, auf deren Grundlage er nach 1945 Brücken über den Rhein baute und "verständigungspolitische Partner« (Hans Manfred Bock) aufspürte, die ihm im eigenen Land Glaubwürdigkeit verliehen und es ihm erlaubten, zuweilen zwischen Politik und Wissenschaft, aber zumeist auf dem zivilgesellschaftlichen Feld der deutsch-französischen Historikerbeziehungen die

\footnotetext{
${ }^{142}$ Robert Schuman an Konrad Adenauer, 5.6.1958; Konrad Adenauer an Robert Schuman, 24.6.1958; BAK, B 136, Bd. 3036.

143 Tagungsbericht von Eugen Ewig, 2.6.1961; BAK, B 250, Bd. 7.

${ }^{144}$ Fritz HARTUNG u.a. (Hg.), Das Reich und Europa, Leipzig ${ }^{2} 1941$, Vorwort S. VII.
} 
Verständigung zu fördern. Diese für Mittler determinierende »doppelte Responsivität« konnte er nun in einer Dialektik von wissenschaftlicher Kompetenz und zivilgesellschaftlichem Engagement in die sich entwickelnden transnationalen Dialogsstrukturen zwischen beiden Ländern einbringen. Die Rückbesinnung auf das Mittelalter bzw. die christlich-abendländische Kultur hatte dabei in der Nachkriegszeit sowohl in der Geschichtswissenschaft als auch in der Politik Konjunktur und ermunterte nicht wenige Historiker bei dem Wettlauf um knappe Ressourcen zu einer Neuausrichtung ihrer Mobilisierungsstrategien. Ewig mußte auf den christlich-abendländischen Zug nicht erst aufspringen, zeugte sein bisheriges Lebenswerk und sein Denken doch gerade auf diesem Feld von einer beachtlichen Kontinuität über die politischen Brüche in der deutschen Geschichte des 20. Jahrhunderts hinweg. Ohne hier in apologetische Züge zu verfallen, läßt sich für Eugen Ewig zweifellos festhalten, daß es ihm auch während des "Dritten Reiches" gelang, die ihm u.a. von Wilhelm Levison vermittelten wissenschaftlichen Standards zu wahren. So fiel es ihm nach 1945 leichter als anderen, aktuelle Zeitstimmungen und neue gesellschaftliche Interessen aufzunehmen, um sie wissenschaftspolitisch zu institutionalisieren. Das in Netzwerken und freundschaftlichen Beziehungen erworbene soziale Kapital konnte er als »créateur« und »acteur « ${ }^{145}$ nun nicht alleine bei der Gründung und Institutionalisierung einer neuen wissenschaftlichen Mittlerinstitution, der Deutschen Historischen Forschungsstelle in Paris, einbringen; auch in anderen Bereichen beteiligte er sich an der Verdichtung von transnationalen Netzwerken. Mögen diese Aktivitäten auch auf einen kleinen elitären Kreis beschränkt geblieben sein, so besteht doch kein Zweifel, daß Eugen Ewig zu jener »relativ breite[n] Generation von Mittlern ${ }^{146}$ gehörte, die im deutsch-französischen Kontext ab Ende der 1950er Jahre innerhalb der gesellschaftlichen bzw. wissenschaftlichen Austauschinstitutionen heranwuchsen. Die bislang nur unzureichenden Informationen über ihre Lebenswege und identitätsstiftenden Schlüsselerlebnisse sollte für die Forschung Grund genug sein, sich ihrer in Zukunft verstärkt anzunehmen.

${ }^{145} \mathrm{Vgl}$. Hans Manfred BocK, Créateurs, organisateurs et vulgarisateurs. Biographies de médiateurs socio-culturels entre la France et l'Allemagne au $\mathrm{XX}^{\mathrm{e}}$ siècle, in: Revue d'Allemagne et des pays de langue allemande 33 (2001) 1, S. 453-467.

146 BOCK, Vom Beruf des kulturellen Übersetzens (wie Anm. 7), S. 13. 